\title{
Regulation of hepatic differentiation of human embryonic stem cells by calcium silicate extracts for liver injury repairing
}

\author{
Lu Zheng ${ }^{\mathrm{a}, \mathrm{b}}$, Dongyuan Lü ${ }^{\mathrm{a}, \mathrm{b}}$, Fan Zhang ${ }^{\mathrm{a}, \mathrm{b}}$, Min Xing ${ }^{\mathrm{c}}$, Xiaoya Wang ${ }^{\mathrm{c}}$, Xiaohua Jia ${ }^{\mathrm{d}}$, \\ Xinyu Shu ${ }^{\mathrm{a}, \mathrm{b}}$, Peiwen $\mathrm{Li}^{\mathrm{a}, \mathrm{b}}$, Shouqin Lü ${ }^{\mathrm{a}, \mathrm{b}}$, Jiang Chang ${ }^{\mathrm{c}, * *}$, Mian Long ${ }^{\mathrm{a}, \mathrm{b}, *}$ \\ ${ }^{a}$ Center of Biomechanics and Bioengineering, Beijing Key Laboratory of Engineered Construction and Mechanobiology and Key Laboratory of Microgravity \\ (National Microgravity Laboratory), Institute of Mechanics, Chinese Academy of Sciences, Beijing 100190, China \\ ${ }^{\mathrm{b}}$ School of Engineering Science, University of Chinese Academy of Sciences, Beijing 100049, China \\ c Biomaterials and Tissue Engineering Research Center, Shanghai Institute of Ceramics, Chinese Academy of Sciences, Shanghai 200050, China \\ ${ }^{\mathrm{d}}$ CAS Key Laboratory of Molecular Imaging, Institute of Automation, Chinese Academy of Sciences, Beijing 100190, China
}

\section{A R T I C L E I N F O}

Article history:

Received 27 May 2020

Revised 11 June 2020

Accepted 12 June 2020

\section{Keywords:}

Human embryonic stem cells

Hepatic differentiation

Hepatocyte-like cells

Calcium silicate extracts

Liver injury repair

\begin{abstract}
A B S T R A C T
Directing embryonic stem cell (ESC)-derived hepatocytes is critical in understanding hepatic differentiation and applying cell-based treatment to severe liver diseases. While growth factor-based strategies are widely used, using chemical cues could present an alternative to optimize the strategies for stem cell differentiation. Here, for the first time, an inorganic calcium silicate (CS, $\mathrm{CaSiO}_{3}$ )-based approach, together with a modified four-stage differentiating protocol, was proposed to quantify the effects of CS extracts on inducing hepatic differentiation of human ESCs (H9 cells). The roles of CS-activated H9 cells in liver injury repair were tested by cell tracking and immunohistochemical staining. Results indicated that high concentrations of CS extracts initially enhance definitive endodermal (DE) lineage, followed by gradual DE differentiation at low CS concentrations. The order of CS addition is also crucial, since the presence at stemness stage and the absence at DE stage could optimize hepatic differentiation capacity of H9 cells, resulting in optimized cells that differentiate into functional hepatocyte-like cells. The addition of CS extracts at precursor hepatocyte stage enhances their maturity, which favors the turnover of liver injury in $\mathrm{CCl}_{4}$-treated mice. These results provide an insight into applying bioactive inorganic biomaterials to foster hepatic differentiation of human ESCs for cell therapy.
\end{abstract}

(c) 2020 Elsevier Ltd. All rights reserved.
Abbreviations: 7-AAD, 7-amino-actinomycin; ALB, albumin; ANOVA, Analysis of variance; BMSCs, Bone marrow mesenchymal stem cells; CK18, cytokeratin 18; CS, Calcium silicate; DE, Definitive endodermal lineage; DEX, Dexamethasone; DPBS, Dulbecco's phosphate-buffered saline; FOXA2, forkhead box protein A2; hDPSCs, Human dental pulp stem cells; hESCs, Human embryonic stem cells; HLCs, Hepatocyte-like cells; HGF, hepatocyte growth factor; hMSCs, human mesenchymal stem cells; HNF- $4 \alpha$, hepatocyte nuclear factor- $4 \alpha$; hPDLs, human periodontal ligament cells; hUSCs, human urine-derived stem cells; ICG, Indocyanine green; ICP, Inductive Coupled Plasma Emission Spectrometer; mAbs, monoclonal antibodies; M-H, Hepatocyte maturation; OSM, Oncostatin M; PAS, Acid-Schiff stain; PEG, Polyethylene glycol; Pre-H, Precursor hepatocytes; RT, Room temperature; SEM, Scanning electron microscopy; STEM, Stemness maintenance; USCs, Urine-derived stem cells; XRD, X-ray diffraction.

* Corresponding author at: Institute of Mechanics, Chinese Academy of Sciences, Beijing 100190, China.

** Co-corresponding author at: Shanghai Institute of Ceramics, Chinese Academy of Sciences, Shanghai 200050, China.

E-mail addresses: jchang@mail.sic.ac.cn (J. Chang), mlong@imech.ac.cn (M. Long).

\section{Introduction}

The liver performs a variety of functions essential for metabolism, detoxification, synthesis, and secretion. Various liver diseases lead to liver failure and irreversible liver damage, which is risky and fatal beyond the self-repairing potential of liver regeneration [1]. Liver transplantation is an effective therapy, but the shortage of available donors, waiting list mortality, high cost of surgery, and immunological rejection remain highly problematic $[2,3]$. Thus, the development of alternative therapeutic strategies is urgent for patients with severe liver diseases. Hepatocytes, as dominant parenchymal hepatic cells, play a pivotal role in the majority of liver mass and hepatic functions [4]. A possible effective strategy for repairing hepatic function is to transplant sufficient hepatocytes or use a bioartificial liver supporting system [5]. To do so, a vast amount of hepatocytes (at least $5 \times 10^{9}$ cells) is required for therapeutic purposes. Considering that these cells are difficult to proliferate in vitro [6], it is urgent to find novel sources of functional hepatocytes. 
Stem cells could serve as one of the sources in liver damage repair and regeneration due to their pluripotent differentiation potential [7-9]. Human embryonic stem cells (hESCs) are capable of proliferating in vitro and differentiate into most somatic cell types when cultured under appropriate conditions [10-12]. A variety of methods are utilized to differentiate hESCs into hepatocytes in vitro, most of which apply growth factors and cytokines, such as activin A, Wnt-3a, hepatocyte growth factor (HGF), and oncostatin M (OSM) [13-15]. Other biochemical regulators of small molecules [16,17], glucocorticoids, and exogenous factors [14,1820] are also used for hepatogenic induction. Transcription factors such as forkhead box protein A2 (FOXA2), FOXA3, and hepatocyte nuclear factor- $4 \alpha$ (HNF- $4 \alpha$ ) are usually applied to improve the differentiation efficiency of pluripotent stem cells [21]. These ESCderived cells display hepatic characteristics, suggesting the possibility of generating hepatocyte-like cells (HLCs) from ESCs as an alternative source of functional hepatocytes. However, several issues remain unresolved along this line, such as hereditary instability, difficulty in large-scale production $\left(\sim 10^{10}\right.$ cells), long differentiation time, and high cost. In particular, the quality and function of HLCs exhibit a disparity with primary hepatocytes in vivo, confining the therapeutic application of ESC-derived HLCs. Thus, developing new effective ways to obtain matured HLCs with well-defined functions and high efficiency is required.

Recent studies suggest that functional biomaterials exert extensive potency to regulate the fate of stem cells. Evidence indicates that silicate bioceramics could promote the proliferation and fate of various stem cell types [22-24]. As a new type of $\mathrm{Ca}-\mathrm{Si}$ bioceramic biomaterial, calcium silicate $\left(\mathrm{CS}, \mathrm{CaSiO}_{3}\right)$ has attracted much attention in the past decade, due to its excellent bioactivity and biocompatibility in directing stem cell differentiation. For example, CS-based materials promote osteogenic differentiation from human mesenchymal stem cells (hMSCs), human dental pulp stem cells (hDPSCs), and human periodontal ligament cells (hPDLs) [25-28]. Applying tricalcium silicate enhances hDPSC proliferation and odontogenic differentiation [22]. Our previous observations indicated that stemness markers increase over short periods, but decrease over extended periods when culturing hESCs in CS-supplemented medium [29], implying that the effects of CS extracts on hESC stemness maintenance could be bidirectional in a time-dependent manner. For the purpose of hESC differentiation over long duration, we hypothesized that CS extracts could potentiate the directional differentiation of hESCs into HLCs. To date, no research addresses the regulation of CS extracts on ESC differentiation into hepatocytes, and the related hepatic functions.

Here, we investigated how CS extracts regulate the differentiating potency of hESCs and manipulate the maturity of in vitro differentiated HLCs in liver injury repair. Specifically, hepatic differentiation of hESCs was studied in systematically-varied concentrations and addition orders of CS extracts, together with a modified fourstage differentiating strategy to induce hESC differentiation from pluripotent cells through definitive endodermal lineage and precursor hepatocytes to HLCs. Next, the impact of CS extracts on liverspecific functions of HLCs was determined. CS-activated HLCs were found to favor liver injury repair in $\mathrm{CCl}_{4}$-treated mice.

\section{Materials and methods}

\section{1. hESC culture and induction of hepatic differentiation}

Human embryonic stem cell line H9 were obtained from WiCell Research Institute (Madison, WI, USA). hESCs were grown on a Matrigel (Corning, NY, USA) -coated polystyrene dish (Thermo Fisher, MA, USA) in PSCeasy medium [modified essential 8 medium] (Cellapy, Beijing, China) at $37^{\circ} \mathrm{C}$ in $5 \%(\mathrm{v} / \mathrm{v}) \mathrm{CO}_{2}$ atmosphere. The medium was changed daily, and routine passage of hESCs was performed via ReLeSR ${ }^{\mathrm{TM}}$ (Stem Cell Technologies, Vancouver, BC, Canada). Briefly, digestion occurred for 3 min after washing twice with Dulbecco's phosphate-buffered saline (DPBS, Thermo Fisher). Digested undifferentiated clones were collected by patting the dish gently, followed by pipetting them onto a glass coverslip precoated with Matrigel.

To direct the differentiation of H9 cells into HLCs, the cells were pre-cultured in PSCeasy medium (denoted as STEM medium) for $24 \mathrm{~h}$ to reach stable attachment, then cultured for another three days in the same medium, followed by an additional three days in RPMI medium (Gibco, MA, USA) supplemented with 100 ng/mL activin A (PeproTech, Rocky Hill, USA), 50 ng/mL Wnt-3a (PeproTech), and 5\% FBS (Thermo Fisher) (denoted as DE inducing medium). Subsequent five-day culture was conducted in HCM medium (LONZA, Walkersville, MD, USA) supplemented with $1 \%$ DMSO (Sigma-Aldrich, St. Louis, MO, USA), 100 ng/mL FGF-4 (PeproTech), and $100 \mathrm{ng} / \mathrm{mL}$ BMP-2 (PeproTech) (denoted as Pre-H inducing medium), followed by a final two-day culture in HCM medium supplemented with $20 \mathrm{ng} / \mathrm{mL}$ HGF (R\&D, Minneapolis, MN, USA), $20 \mathrm{ng} / \mathrm{mL}$ OSM (R\&D), $1 \mathrm{ng} / \mathrm{mL}$ SB431542 (PeproTech), and $100 \mathrm{nM}$ dexamethasone (DEX, Sigma-Aldrich) (denoted as $\mathrm{M}-\mathrm{H}$ inducing medium). This protocol, modified from literature [30-32], was defined as a four-stage strategy of hepatic differentiation, that is, stemness maintenance (STEM or S), definitive endodermal lineage (DE or D), precursor hepatocytes (Pre-H or P), and hepatocyte maturation (M-H or M), to promote HLCs from H9 cells (Fig. 1A).

\subsection{Preparation and characterization of CS powder and extracts}

Primary CS powder were prepared as described previously [29,33], Briefly, an aqueous solution of $\mathrm{Na}_{2} \mathrm{SiO}_{3}(1 \mathrm{~mol} / \mathrm{L})$ and an aqueous solution of $\mathrm{Ca}\left(\mathrm{NO}_{3}\right)_{2}(1 \mathrm{~mol} / \mathrm{L})$ were continuously mixed by stirring at ambient temperature overnight (molar ratio: $\left.\mathrm{Na}_{2} \mathrm{SiO}_{3}: \mathrm{Ca}\left(\mathrm{NO}_{3}\right)_{2}=1: 1\right)$. The resultant $\mathrm{CS}$ suspension was filtered and washed first with deionized water and subsequently, with ethanol. After drying at $80{ }^{\circ} \mathrm{C}$ overnight and baking at $800{ }^{\circ} \mathrm{C}$ for $2 \mathrm{~h}$, the CS powder was sieved to obtain CS particles using a mesh with 100 - to $150-\mu$ m diameter pores. Morphology of CS particles initially in powder or soaked in DMEM/F12 medium (Gibco) were examined using a scanning electron microscope (SEM) (Hitachi 8010, Japan) operated at a voltage of $10 \mathrm{kV}$. Effects of heat treatment and chemical composition on phase transition behaviors of CS particles were investigated using X-ray diffraction (XRD, D/max 2550 V, Rigaku, Japan).

To obtain the CS extracts from the CS particles, $1 \mathrm{~g}$ CS particles was added into a culture dish, mixed, and soaked in $5 \mathrm{~mL}$ DMEM/F12 for $12 \mathrm{~h}$, followed by gentle pipetting and re-soaking for an additional $12 \mathrm{~h}$. The supernatant was collected and filtered using a Millipore filter (size of Millipore $=0.22 \mu \mathrm{m}$ ). Collected CS extracts were diluted with the respective medium at a ratio of 1 : 64 (high concentration) or 1: 256 (low concentration), prior to CS addition into the culture plate with pre-seeded H9 cells at distinct stages of hepatic differentiation (short vertical lines in Fig. 1B). To investigate the effects of ionic products on hepatic differentiation, the ingredients of various ions released in CS extracts, and diluted at the above ratios with three types of basal media (cf. Section 2.1), were determined using Inductive Coupled Plasma Emission Spectrometer (ICP). The CS extract-supplemented medium was added onto Matrigel-coated coverslips placed on polystyrene dishes for $24 \mathrm{~h}$ before collection, and the contents of the ions were determined by ICP to exclude the effect of Matrigel.

\subsection{Sequential addition of CS extracts in H9 cell differentiation}

To test the effects of CS extracts on the directed differentiation of $\mathrm{H} 9$ cells to HLCs, the four-stage protocol was segregated into 


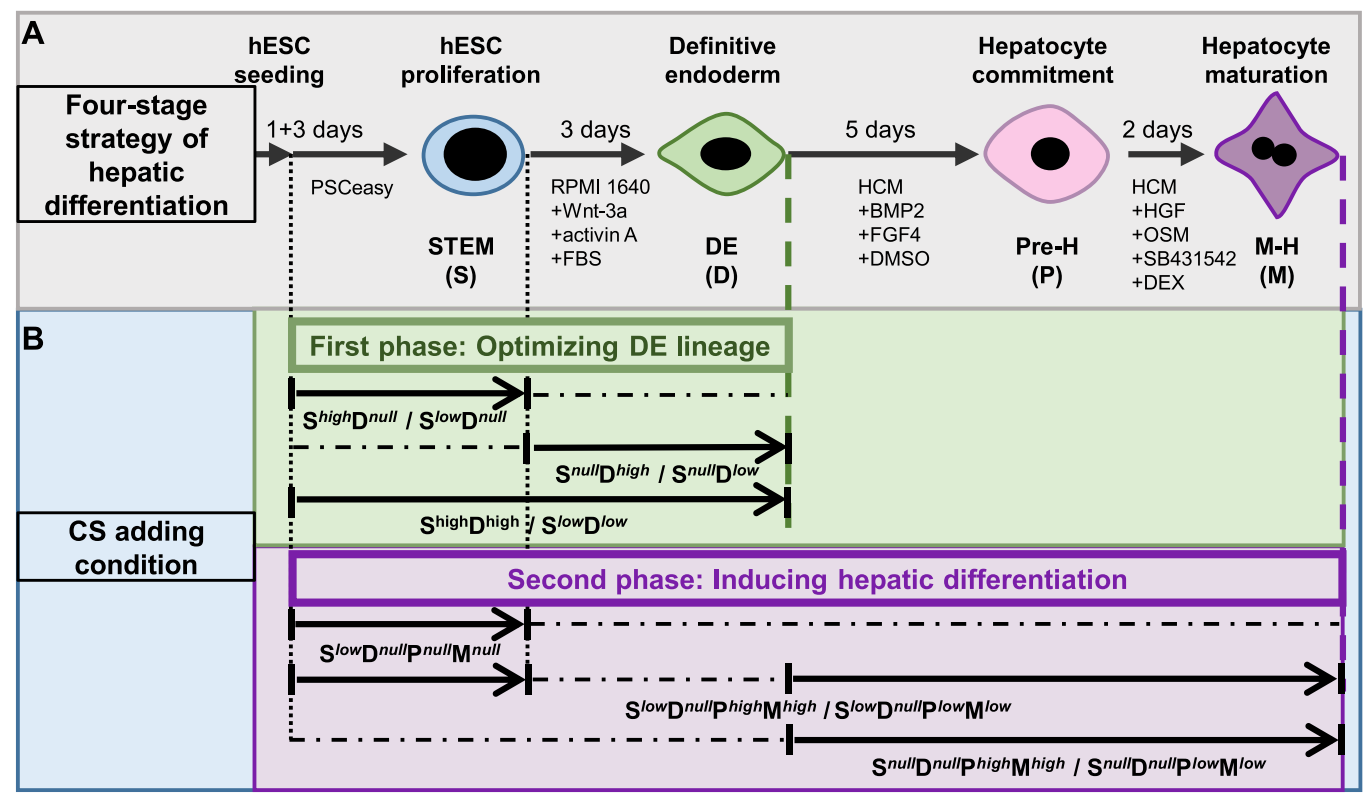

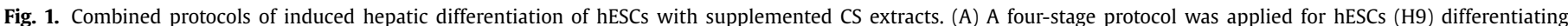

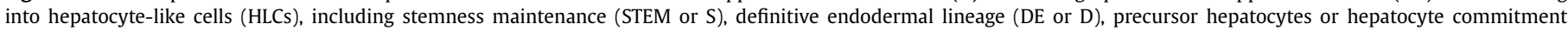

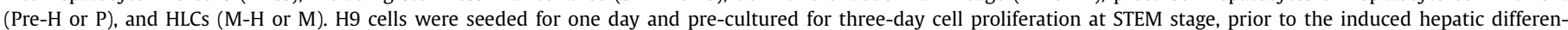

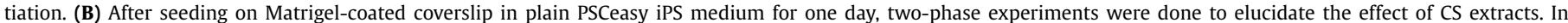

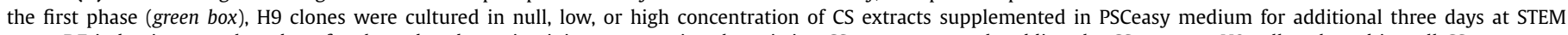

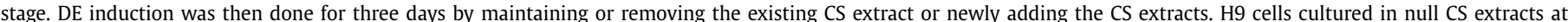

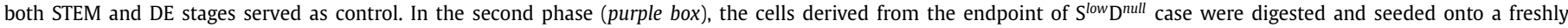

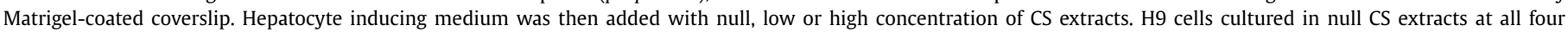

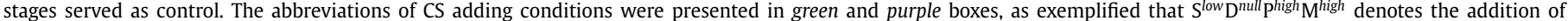
low, null, high, and high concentrations of CS extracts at STEM, DE, Pre-H, and M-H stages, respectively.

two phases. The first phase included STEM and DE stages, with the order of addition of CS extracts summarized in Fig. 1B. At high or low CS concentration, the CS extracts were added starting at the STEM or DE stage separately or spanning over the two stages. Culturing H9 cells in null CS extracts served as the control. The second phase spanned over Pre-H and $\mathrm{M}-\mathrm{H}$ stages, where high, low, or null CS extracts were added in respective media, as summarized in Fig. 1B. Here, the optimized low concentration and addition order of CS extracts in the first phase were applied to further test the CS concentration dependence on hepatic differentiation of H9 cells in the second phase. Culturing in null CS extracts in this phase served as the control.

\subsection{Immunofluorescence staining and confocal microscopy}

Cells cultured on Matrigel-coated glass coverslips were rinsed thrice in DPBS ( $\mathrm{pH} 7.2$ ), fixed in $4 \%$ paraformaldehyde (Amresco, Washington, USA) for $15 \mathrm{~min}$, and permeabilized with $0.4 \%$ Triton X-100 (Sigma-Aldrich) for $10 \mathrm{~min}$. After blocking non-specific epitopes using 1\% BSA/DPBS (Sigma-Aldrich) at $37{ }^{\circ} \mathrm{C}$ for $1 \mathrm{~h}$, the cells were stained with respective primary monoclonal antibodies (mAbs) at $37{ }^{\circ} \mathrm{C}$ for $1 \mathrm{~h}$, incubated at $4{ }^{\circ} \mathrm{C}$ overnight, and rinsed five times with DPBS. Thereafter, the labeled secondary antibodies in $1 \%$ BSA were added and incubated at $37{ }^{\circ} \mathrm{C}$ for $1 \mathrm{~h}$. After washing five times with DPBS, Hoechst 33342 (Invitrogen, Eugenen, Oregon, USA) was added to the collected samples and incubated for $15 \mathrm{~min}$ at room temperature (RT). After washing five times with DPBS, the samples were then stored at $4{ }^{\circ} \mathrm{C}$ for examination by confocal laser scanning microscopy (Zeiss L710, Germany) within two days.

The stemness or directed differentiation state of H9 cells was identified by their specific biomarkers at the respective stages. Primary mouse mAbs to SOX17 (ab84990, Abcam, Cambridge, UK) with secondary Alexa Fluor 594-conjugated polyclonal goatanti-mouse antibodies (ab150120, Abcam) and primary rabbit polyclonal antibodies to CXCR4 (ab1670, Abcam) with secondary Alexa Fluor 647-conjugated polyclonal goat-anti-rabbit antibodies (ab150077, Abcam) were used for testing definitive endodermal lineage. Primary chicken polyclonal antibodies to albumin (ALB) (ab106582, Abcam) with secondary Alexa Fluor 488-conjugated polyclonal donkey-anti-chicken antibodies (ab150172, Abcam) and Alexa Fluor 647-conjugated rabbit mAbs to cytokeratin 18 (CK18) (ab194125, Abcam) were used for testing hepatocyte-specific phenotypes.

\subsection{Flow cytometry analysis}

To detect cell apoptosis, an annexin V-PE Apoptosis Detection Kit I (Becton Dickinson, Minneapolis, MN, USA) was used. Briefly, the cells at DE stage were digested with $0.25 \%$ trypsin (Hyclone, Logan, Utah, USA) and fixed in $4 \%$ paraformaldehyde for $10 \mathrm{~min}$ at RT. After rinsing in DPBS twice, the cells were incubated with annexin V-FITC and 7-amino-actinomycin (7-AAD) solution for $1 \mathrm{~h}$ in the dark at RT, and then analyzed using a FACS Canto II flow cytometer (Becton Dickinson, Minneapolis, MN, USA).

\subsection{Quantitative PCR}

Cultured cells were collected at the endpoint of each phase. Total RNA was harvested using a commercial RNA extraction kit (Tiangen, Beijing, China). The corresponding cDNA was generated using commercial ReverTra Ace-a Kit (Toyobo, Osaka, Japan) with $1 \mu \mathrm{g}$ of RNA in a total volume of $20 \mu \mathrm{L}$ per reaction. A reverse transcriptase-polymerase chain reaction was performed using a quantitative real-time amplification system (QuantStudio 7, Thermo Fisher). Briefly, a total volume of $10 \mu \mathrm{L}$ amplification mixture per well was amplified as follows: denaturation at $95{ }^{\circ} \mathrm{C}$ for $10 \mathrm{~s}$, annealing at $60{ }^{\circ} \mathrm{C}$ for $30 \mathrm{~s}$, and extension at $72{ }^{\circ} \mathrm{C}$ for $30 \mathrm{~s}$. Biomarker genes were evaluated accordingly - SOX17 and CXCR4 
at the DE stage and $A L B$ and CK18 for HLCs. GAPDH was used as an internal reference. The relative expression level of these genes for all the cases was normalized to the case in null CS extracts at $\mathrm{M}-\mathrm{H}$ stage (that is, the control case) or to the case in high CS concentration at the DE stage (that is, $\mathrm{S}^{\text {high }} \mathrm{D}^{\text {high }}$ in Fig. 1B), since gene expression after one-day induction in the control case is too low to apply.

\subsection{Scanning electron microscope (SEM) imaging}

Cultured cells were washed three times in $\mathrm{Ca}^{2+}$ - and $\mathrm{Mg}^{2+}$-free DPBS and then fixed with $0.25 \%$ glutaraldehyde at RT overnight. After removing glutaraldehyde, the fixed cells were washed with DPBS three times, followed by dehydration in an ethanol gradient, with final drying in a vacuum for $4 \mathrm{~h}$. Image acquisition was performed using a SEM machine (FEI Quanta 200, USA).

\subsection{ELISA test for ALB secretion}

HLC ALB secretion was determined using an ELISA Kit (Bethyl, Montgomery, Alabama, USA). Briefly, the supernatant was collected and then centrifuged at $1000 \mathrm{rpm}(170 \times \mathrm{g})$ for $5 \mathrm{~min}$. Supernatant or standard ALB sample (100 $\mu \mathrm{L})$ was added into a 96-well plate pre-coated with anti-human ALB primary antibodies. After incubation at RT for $1 \mathrm{~h}$ and four washes, an additional $100 \mu \mathrm{L}$ anti-ALB detection antibodies were added and incubated at RT for $1 \mathrm{~h}$. After rinsing four times, $100 \mu \mathrm{L}$ streptomycin-conjugated horseradish peroxidase was added, incubated for $30 \mathrm{~min}$, and washed four times, followed by the addition of $100 \mu \mathrm{L}$ chromogenic substrate tetramethyl benzidine for an additional $30 \mathrm{~min}$ incubation in the dark. After adding $100 \mu \mathrm{L}$ stop solution to each well, the plate was examined at $450 \mathrm{~nm}$ using the iMark $^{\mathrm{TM}}$ microplate reader (BIORAD, Hercules, CA, USA). A four-parameter standard curve was obtained using the absorbance ratio of the yellow product to the value of the standard sample, as per the manufacturer's instructions.

\subsection{Glycogen synthesis and indocyanine green (ICG) engulfment}

Glycogen synthesis was determined using a commercial kit and a periodic acid-Schiff stain (PAS) (Nanjing Jiancheng Bioengineering Institute, Nanjing, Jiangsu, China). Briefly, the powders of periodic acid and Schiff's reagent were dissolved in their respective diluting solutions and balanced at RT for 20 min. Cells were fixed with $95 \%$ ethanol for 2-5 min and washed with flowing water for $1 \mathrm{~min}$. The periodic acid solution was added to the fixed cells and incubated for $15 \mathrm{~min}$. After rinsing with flowing water for $5 \mathrm{~min}$, Schiff's solution was added and incubated for $15 \mathrm{~min}$, followed by washing with flowing water for 30-60 s. Finally, hematoxylin staining solution was added, incubated for 20-30 s, and washed out. The stained cells were visualized using an optical microscope (Olympus IX71, Tokyo, Japan).

ICG engulfment by HLCs was tested using a commercial kit (Sigma-Aldrich). Briefly, ICG powders were dissolved in water and diluted in $\mathrm{M}-\mathrm{H}$ inducing medium at a final concentration of 1 $\mathrm{mg} / \mathrm{mL}$. The solution was added to cells pre-washed with DPBS and incubated at $37{ }^{\circ} \mathrm{C}$ for $1 \mathrm{~h}$. Cells were washed with DPBS and fixed with $4 \%$ paraformaldehyde, followed by rinsing before visualization using an optical microscope.

\subsection{Simple western analysis}

Total protein was harvested from induced HLCs using RIPA medium with protease and phosphatase inhibitors, and quantified using a Bicinchoninic acid (BCA) assay kit (Pierce ${ }^{\circledR}$, Thermo Scientific). Simple western analysis was performed using the $\mathrm{WES}^{\mathrm{TM}}$ device (ProteinSimple, San Jose, CA, USA) [34]. Briefly, $3 \mu$ L protein was loaded onto the plate, labeled with a biotin reagent, and detected by streptavidin-horseradish peroxidase chemiluminescence, with the biotinylated ladder serving as control. Each protein peak was measured automatically using Compass ${ }^{\mathrm{TM}}$ software (Version 4.0.0, Protein-Simple) and normalized to the value of GAPDH.

\subsection{Animal treatment and HLC transplantation}

Five- to seven-week-old female NOD/SCID mice were purchased from Charles River (Beijing, China) and fed a routine diet for one week before $\mathrm{CCl}_{4}$ treatment. All animal research and care procedures were approved by the Animal Experimentation Committee of Institute of Mechanics Chinese Academy of Sciences. $\mathrm{CCl}_{4}$ (Solarbio, Beijing, China) was diluted using corn oil (Solarbio, Beijing, China) in $20 \%(\mathrm{v} / \mathrm{v})$ and fully mixed by magnetic stirrers for $4 \mathrm{~h}$ [35]. Intraperitoneal injection volume of $\mathrm{CCl}_{4}$ solution was administered at a concentration of $1.7-2.8 \mu \mathrm{L} / \mathrm{g}$, with mouse weight varying between 15-24 g. All mice were injected twice a week for four weeks. Approximately $10^{6}$ HLCs induced by CS extracts in the $S^{\text {low }} \mathrm{D}^{\text {null }} \mathrm{P}^{\text {low }} \mathrm{M}^{\text {low }}$ case and control HLCs without the activation of CS extracts were transplanted into the caudal vein using U-40 insulin pens (B|BRAUN, Melsungen, Germany). CM-Dil (Invitrogen, Eugenen, Oregon, USA) was used to track the injected HLCs in the liver.

\subsection{In vivo tracking and in vitro measurement of transplanted cells}

At day three or week four after HLC transplantation, the mice were anesthetized using phenobarbitone. The abdomen was opened, and the liver was exposed for exanimation by confocal laser scanning microscopy (Zeiss L880, Germany). The structure of the liver edge was recognized by liver autofluorescence, while the exogenous HLCs were stained with CM-Dil. The entire liver was extracted and the HLC-emitted fluorescence was detected by the In Vitro Imaging System (IVIS) spectrum (PerkinElmer, USA) [36,37] at the end of four weeks post-transplantation.

\subsection{Liver injury and repair tests}

During $\mathrm{CCl}_{4}$ injection, whole blood was suctioned periodically by capillary from the inner canthus vein, and plasma was collected after allowing the blood to stand at RT for $4 \mathrm{~h}$, followed by centrifugation at $3500 \mathrm{rpm}(1150 \times \mathrm{g})$ for $10 \mathrm{~min}$ at $4{ }^{\circ} \mathrm{C}$. The activities of alanine aminotransferase (ALT) and aspartate aminotransferase (AST) were tested using corresponding kits (Sigma-Aldrich), as per the manufacturer's instructions. Four weeks after $\mathrm{CCl}_{4}$ injection, the liver was removed and paraffin-embedded for hematoxylin and eosin (HE) and Masson staining. All tests were also conducted at the end of a further four weeks post-HLC transplantation to ascertain liver injury repair.

\subsection{Statistical analysis}

Data were presented as the mean \pm SEM. Two-way analysis of variance (ANOVA) was performed to determine the statistical significance of differences among the two factors of CS concentration and order of CS addition. As for those comparisons of any two groups of the lumped cases (first and second phases), the unpaired two-tailed Student's $t$ test was performed upon passing the normality test, or Mann-Whitney rank sum tests were used if not. $P$ values of less than 0.05 were considered statistically significant. 
Table 1

\begin{tabular}{llll}
\multicolumn{1}{l}{ Ion contents of CS extracts diluted at two ratios (mean \pm SEM). } \\
\hline Basal medium and added CS extracts ${ }^{\mathrm{a})}$ & $\mathrm{Ca}(\mu \mathrm{g} / \mathrm{ml})$ & $\mathrm{P}(\mu \mathrm{g} / \mathrm{ml})$ & $\mathrm{Si}(\mu \mathrm{g} / \mathrm{ml})^{\mathrm{b})}$ \\
\hline PSCeasy at STEM stage & $32.61 \pm 1.24$ & $29.37 \pm 0.04$ & $0.02 \pm 0.00$ \\
$1 / 256$ CS & $32.33 \pm 1.25$ & $29.16 \pm 0.12$ & $0.31 \pm 0.00$ \\
$1 / 64$ CS & $32.91 \pm 1.17$ & $28.75 \pm 0.13$ & $1.11 \pm 0.05$ \\
RPMI 1640 at DE stage & $14.80 \pm 0.57$ & $191.10 \pm 0.26$ & $0.03 \pm 0.01$ \\
$1 / 256$ CS & $14.58 \pm 0.55$ & $192.43 \pm 0.38$ & $0.32 \pm 0.01$ \\
$1 / 64$ CS & $14.68 \pm 0.53$ & $188.07 \pm 0.53$ & $1.19 \pm 0.02$ \\
HBM at Pre-H and M-H stages & $61.79 \pm 2.39$ & $31.87 \pm 0.39$ & $0.05 \pm 0.00$ \\
$1 / 256$ CS & $60.26 \pm 2.19$ & $31.57 \pm 0.14$ & $0.20 \pm 0.00$ \\
$1 / 64$ CS & $61.56 \pm 2.70$ & $31.98 \pm 0.29$ & $0.70 \pm 0.00$ \\
PSCeasy on Matrigel-coated coverslip & $32.30 \pm 1.02$ & $30.00 \pm 0.68$ & $0.04 \pm 0.01$ \\
$1 / 256$ CS & $33.09 \pm 0.86$ & $29.38 \pm 0.71$ & $0.28 \pm 0.06$ \\
$1 / 64$ CS & $33.00 \pm 0.87$ & $29.45 \pm 0.76$ & $1.21 \pm 0.11$ \\
\hline a) CS extracts are diluted in basal medium in a ratio of $1: 256(1 / 256$ or low concentration) \\
or 1:64 (1/64 or high concentration). \\
b) Difference between any one specific case (basal medium supplemented with CS extracts) \\
and control (basal medium with null CS extracts), $P<0.01^{* *}$, and $0.0001^{* * * *}$.
\end{tabular}

\section{Results}

\subsection{Characterizations of CS powder and extracts}

Specialized features of CS powder were quantified using SEM imaging and XRD analysis, presenting the nanoscale size and the characteristic peaks of $\mathrm{CaSiO}_{3}$ (Figure S1). Moreover, ICP analysis was conducted to determine the ionic concentrations in CS extracts. The content of Si ions diluted at high or low CS concentrations was much higher than in the basal medium, whereas the contents of $\mathrm{Ca}$ and $\mathrm{P}$ ions were similar with the basal medium (Table 1). Co-existence of Matrigel with CS extracts induced few effects on the ionic release or maintenance since no differences in the levels of these three types of ions were found in the presence or absence of Matrigel (Figure S2). Collectively, these results implied that the effects of CS extracts are primarily attributed to $\mathrm{Si}$ ions, while the addition of CS extract into Matrigel is applicable in hepatic differentiation of $\mathrm{H} 9$ cells.

\subsection{Cell morphology and growth at STEM and DE stages}

Hepatic differentiation of hESCs generally undergoes different stages, such as pluripotent cells, definitive endodermal lineage, precursor hepatocytes, and HLCs [30]. Here, we modified this fourstage, feeder cell-free strategy to induce hepatic differentiation of hESCs by placing H9 cells on Matrigel-coated glass coverslips (Fig. 1). To guarantee clone adherence on the substrate, the clones were first placed in plain PSCeasy medium for one day to ensure attachment, followed by switching to a medium supplemented with CS extracts for an additional three days of culture. This resulted in similar morphology at all CS concentrations and addition orders (Fig. 2). Specifically, the cells at the STEM stage seemed to form individual tight clones with clear contours (Fig. 2A1-A7) and increased in size post-culture for three days (Fig. 2B1-B7). These observations indicated that H9 cells grew in a well-defined state, providing a phenotype basis for further tests. At the DE stage, the clones became loose and single cells tended to appear at the periphery of the clone (Fig. 2C1-C7). To clarify the features of those cells in the center or at the periphery, an individual clone was segregated into a main body and a surrounding region (Figure S3A). Only a cell that has more than $2 / 3$ clear periphery leaving the clone was denoted as a single cell in the surrounding region. Thus, the main body area and the number of single cells were found to correlate with CS concentration and order of addition. At higher CS concentrations, we observed larger main body areas of the clone (Figure S3B) and an increased number of single cells (Figure S3C). Moreover, the two values were higher in supplemented CS extracts starting at the STEM stage or spanning over STEM and DE stages than that starting at the DE stage or in null CS extracts. At the endpoint of DE induction (Day 3), all cells tended to form a monolayer and no clear boundary was visualized between the main body and surrounding regions (Fig. 2D1-D7). These results implied that the potentials of CS extracts in directing hESC differentiation could be initiated from their morphological changes at DE stage.

\subsection{CS extracts promote DE differentiation}

To quantify the effects of the concentration and the order of addition of CS extracts in directing DE differentiation of H9 cells, two time points of CS addition were set up, one starting at the STEM stage in PSCeasy medium and another starting at the DE stage in DE-inducing medium (Fig. 1). These addition points combined with three concentrations (high, low, and null) served as six cases to systematically test their cooperative impacts (Fig. 3). Null CS extracts at both stages served as controls. Two checkpoints were adopted at the end of the first and third day of the DE stage, respectively, to unravel the short- and long-term responses of $\mathrm{H} 9$ cells. All cases were segregated into three groups representing three distinct orders, that is, adding two concentrations of CS extracts at both STEM and DE stages ( $S^{\text {high }} \mathrm{D}^{\text {high }}$ and $\left.S^{\text {low }} \mathrm{D}^{\text {low }}\right)$, STEM stage alone $\left(S^{\text {high }} \mathrm{D}^{\text {null }}\right.$ and $\left.S^{\text {low }} \mathrm{D}^{\text {null }}\right)$, and DE stage alone $\left(S^{\text {null }} \mathrm{D}^{\text {high }}\right.$ and $S^{\text {null }} \mathrm{D}^{\text {low }}$ ) (Fig. 1).

Two DE biomarkers, CXCR4 and SOX17, were used to examine DE differentiation. At the protein level, CXCR4 and SOX17 were present over the entire clone with high fluorescent intensities at the periphery (Fig. 3A-D). Specifically, these two proteins yielded higher expressions at the high CS concentration (Fig. 3A1-A3 and B1-B3) than those at the low concentration (Fig. 3A4-A6 and B4B6), implying that the capacity of CS extracts in inducing DE differentiation increased with increasing CS concentration during shortterm induction. H9 clones started to loosen, with typical cavities inside the clone at Day 1 (yellow arrows), leading to the appearance of individualized cells at the periphery of the clone (white arrow heads) (Fig. 3D1-D7). These results suggest that high CS concentration promotes rapid initial DE differentiation.

Mean fluorescent intensities (MFIs) per clone in all six cases were estimated and normalized to the control. Both CXCR4 and SOX17 expressions were similar in all three orders at either high (black bars) or low (grey bars) CS concentrations, suggesting that the addition order of CS extracts is unlikely associated with initial DE differentiation. In contrast, their expressions were significantly or moderately enhanced at the high CS concentration than those at the low concentration (Fig. 3E-F), supporting the above CS concentration dependence from confocal images (Fig. 3A-D). Only SOX17 


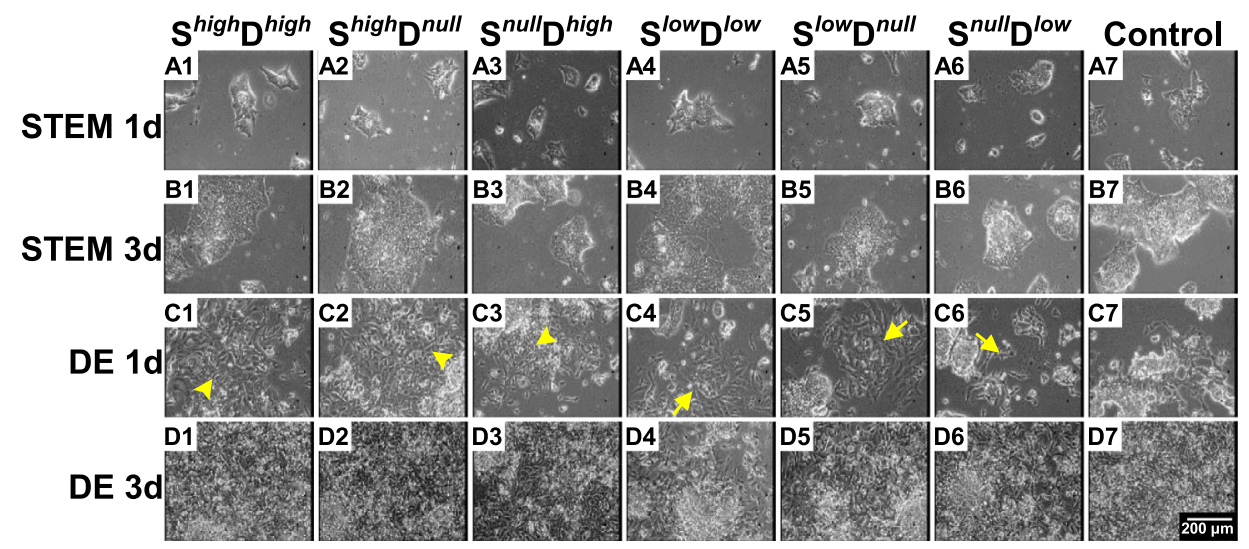

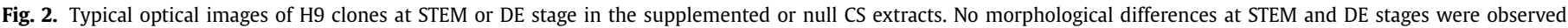

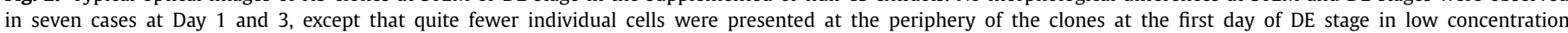
CS-extract medium (C4-C6) (arrows) than those in high concentration (C1-C3) (arrowheads). Scale bar $=200 \mu \mathrm{m}$.

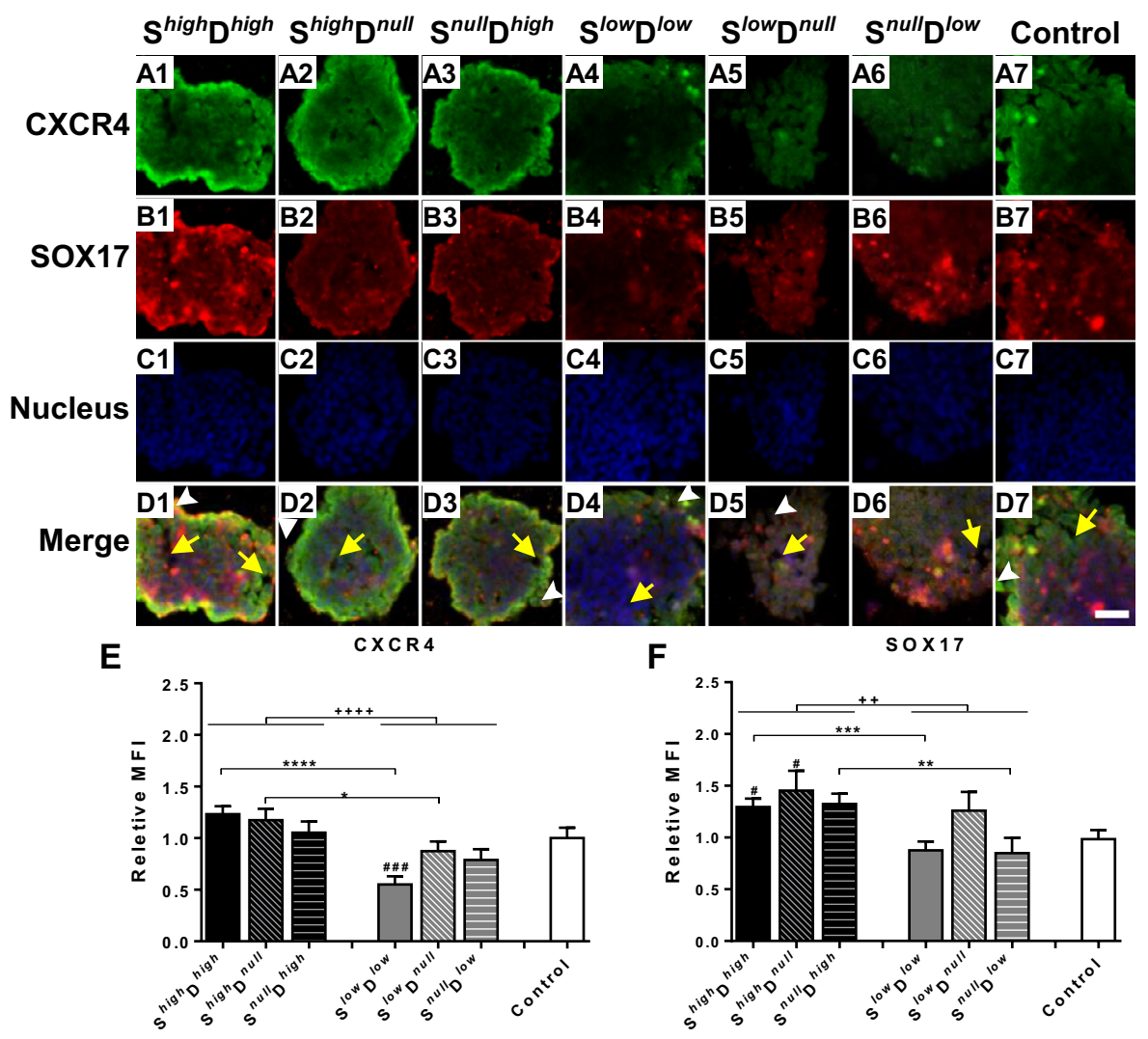

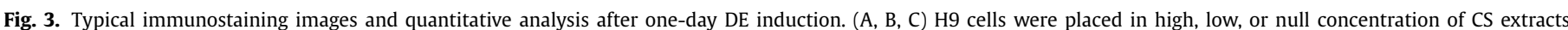

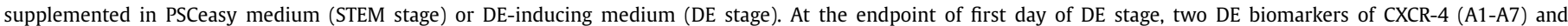

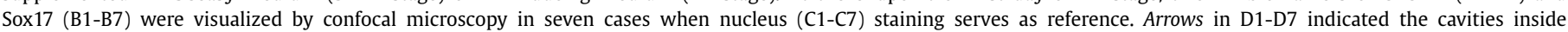

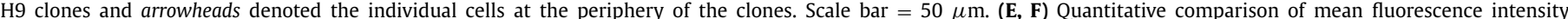

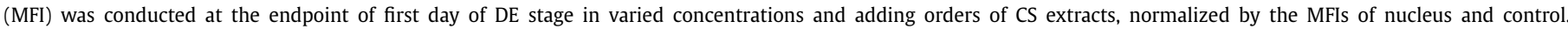

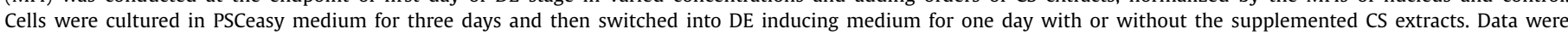

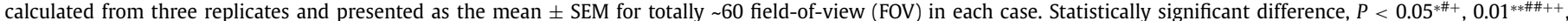

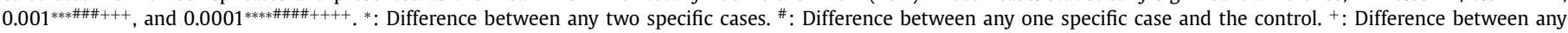
two groups of the lumped cases.

expression in $S^{\text {high }} \mathrm{D}^{\text {high }}$ and $S^{\text {high }} \mathrm{D}^{\text {null }}$ cases at the high CS concentration was higher, but CXCR4 expression in $S^{\text {low }} \mathrm{D}^{\text {low }}$ at the low concentration was lower, as compared to those in the control case (white bar) (Fig. 3F).

After the three-day induction of DE lineage, the clone-specific structures disappeared and the cells dispersed into a monolayer with similar morphologies in all six cases (Fig. 4A-D; Fig. 2D1-D7).
Immunostaining analysis indicated that all cells expressed CXCR4 and SOX17 at moderately-varied degrees, indicating that they differentiated into mature DE lineage cells. Moreover, the MFIs of two biomarkers seemed higher at the low CS concentration (Fig. 4A-D), implying an opposite dependence of CS extract concentration compared to the above short-term DE induction. Quantitative analysis supported these observations, where the MFIs were significantly 


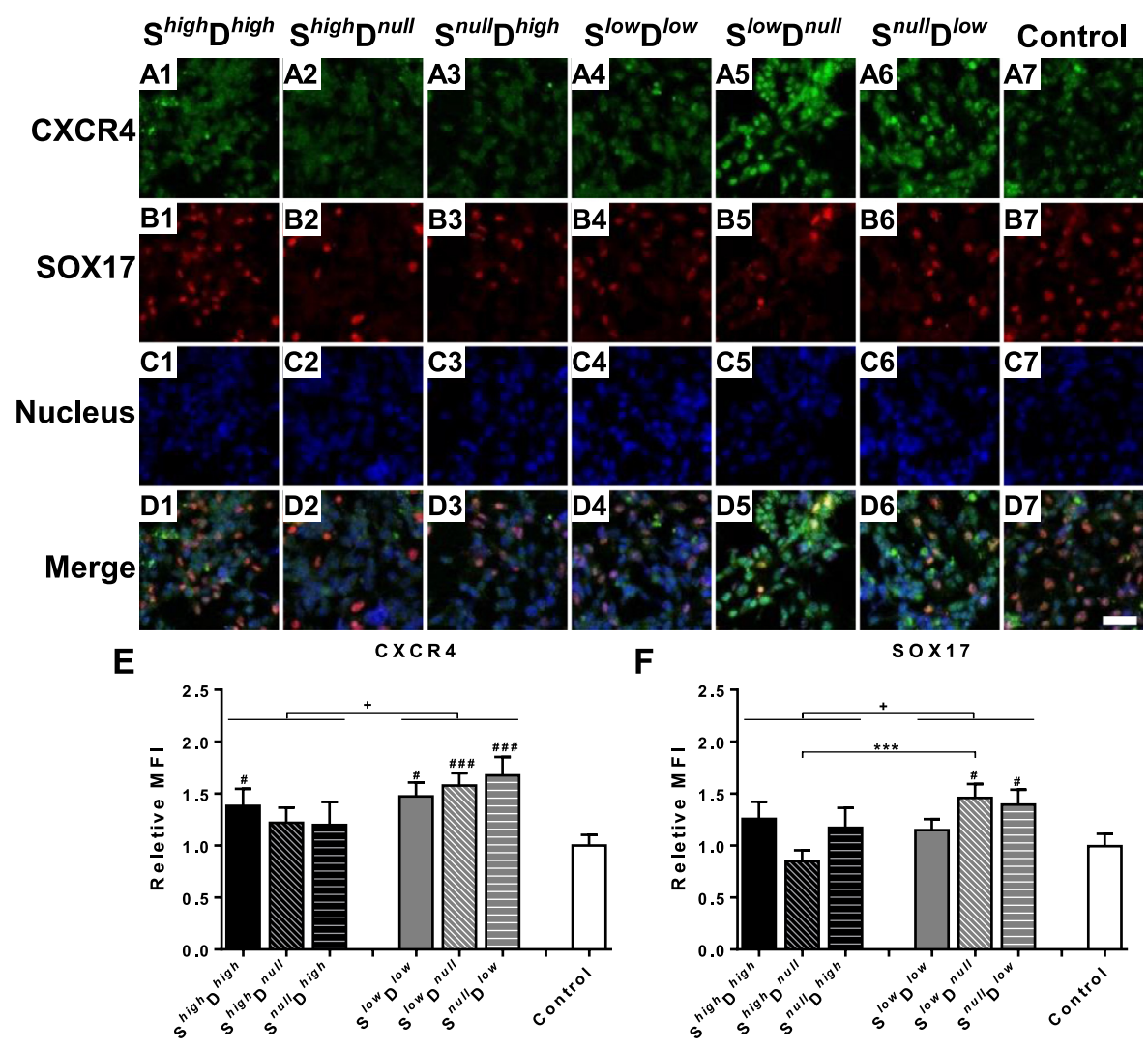

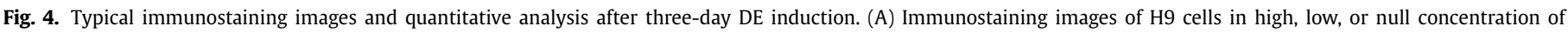

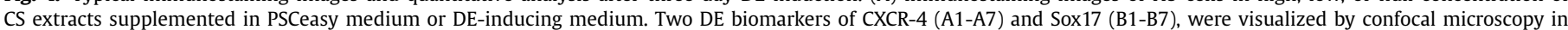

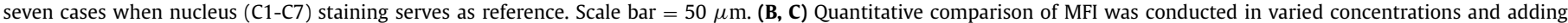

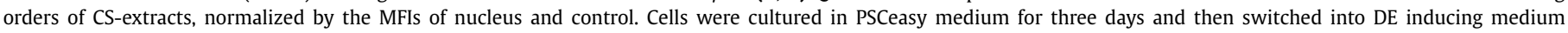

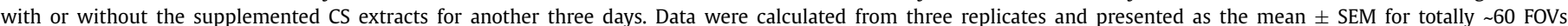

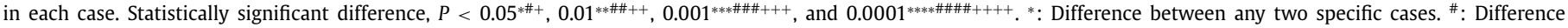
between any one specific case and the control. ${ }^{+}$: Difference between any two groups of the lumped cases.

higher for both CXCR4 and SOX17 expressions at the low CS concentration (Fig. 4E-F). Intriguingly, the dependence on the addition order of CS extracts was also observed at the low concentration where the two biomarker expressions were higher when adding CS extracts at the STEM $\left(S^{\text {low }} \mathrm{D}^{\text {null }}\right)$ or DE $\left(S^{\text {null }} \mathrm{D}^{\text {low }}\right)$ stage than those at both STEM and DE stages ( $S^{\text {low }} \mathrm{D}^{\text {low }}$ ) (Fig. 4E-F). These values in the $S^{\text {low }} \mathrm{D}^{\text {null }}$ and $S^{\text {null }} \mathrm{D}^{\text {low }}$ cases were remarkably higher than that in controls, implying that adding low concentrations of CS extracts alone at the STEM or DE stage favors DE lineage differentiation.

To consolidate the optimized combination of CS concentration and order of addition for hepatic differentiation of H9 cells, gene expression related to DE lineage was tested for short- and longterm induction. Relatively high expression was seen at Day 1 at the high CS concentration in the cases of $S^{\text {null }} \mathrm{D}^{\text {high }}$ for CXCR4 or $S^{\text {high }} \mathrm{D}^{\text {null }}$ and $\mathrm{S}^{\text {null }} \mathrm{D}^{\text {high }}$ for SOX17 (Fig. 5A-B), or at Day 3 at the low concentration in the cases of $S^{\text {null }} \mathrm{D}^{\text {low }}$ for CXCR4 or $S^{\text {low }} \mathrm{D}^{\text {low }}$ and $S^{\text {low }} \mathrm{D}^{\text {null }}$ for SOX17 (Fig. 5C-D). Two exceptional high expressions were observed in the cases of $S^{\text {null }} \mathrm{D}^{\text {high }}$ for CXCR4 or $S^{\text {null }} \mathrm{D}^{\text {high }}$ for SOX17 at Day 3 at the high CS concentration. Noting the differences between gene and protein levels, these gene expressions were not inconsistent with the above immunostaining observations. To further investigate if CS extracts exert cytotoxic effects and affect subsequent hepatic differentiation, apoptotic analysis was conducted for three-day DE-induced cells (Fig. 5E). No difference was found in the percentage of early or late apoptotic cells or viable cells in all six cases, implying that the majority of cells (>80\%) are not apoptotic (Fig. 5F).
Collectively, DE lineage differentiation of $\mathrm{H} 9$ cells was initiated at the high concentration of CS extracts and then gradually matured at the low CS concentration. Adding CS extracts at the STEM or DE stage at the low CS concentration is favorable for harvesting the mature, viable DE cells for hepatic differentiation.

\subsection{CS extracts enhance the differentiation to hepatocyte-like cells}

To reduce labor consumption and simplify experimental operation, the starting point for HLC differentiation was obtained by adding CS extracts at the STEM stage at low CS concentrations and inducing DE lineage differentiation of $\mathrm{H} 9$ cells for three days $\left(S^{l o w} D^{\text {null }}\right)$. This setting was confirmed by well-defined ultrastructures of the cells from SEM images in the two typical cases of $S^{\text {low }} \mathrm{D}^{\text {null }}$ and $\mathrm{S}^{\text {high }} \mathrm{D}^{\text {high }}$ (Figure S4). The clones were tighter in the control than in the other two cases with CS extracts at the first day of the STEM stage (Figure S4A-C). After three-day DE induction, most elongated spindle cells became smoother in the $S^{\text {low }} \mathrm{D}^{\text {null }}$ case than in the $\mathrm{S}^{\text {high }} \mathrm{D}^{\text {high }}$ case (Figure S4J-L), implying that the latter could better serve as the starting point for hepatic differentiation.

HLCs differentiation based on CS concentration dependence was then tested by adding high or low concentrations of CS extracts over Pre- $\mathrm{H}$ and $\mathrm{M}-\mathrm{H}$ stages while $\mathrm{H} 9$ cells in null CS extracts spanning over all four stages served as controls (Fig 1A). The cells were cultured in high, low, or null CS extracts supplemented into HLC-specific inducing medium separately (i.e., $S^{\text {low }} \mathrm{D}^{\text {null }} \mathrm{P}^{\text {null }} \mathrm{M}^{\text {null }}, \mathrm{S}^{\text {low }} \mathrm{D}^{\text {null }} \mathrm{P}^{\text {high }} \mathrm{M}^{\text {high }}, \mathrm{S}^{\text {low }} \mathrm{D}^{\text {null }} \mathrm{P}^{\text {low }} \mathrm{M}^{\text {low }}$, and con- 

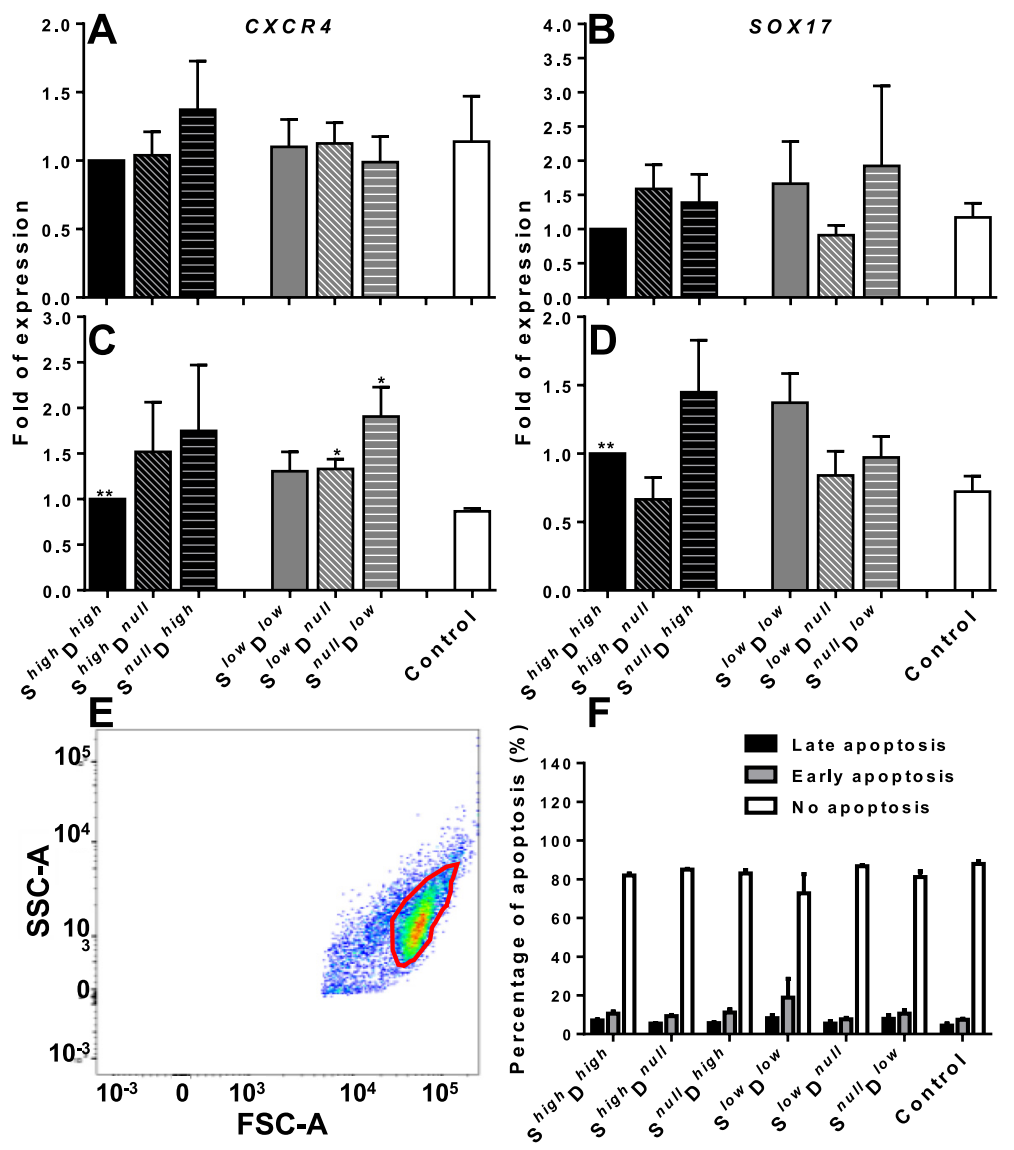

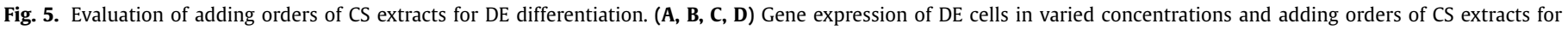

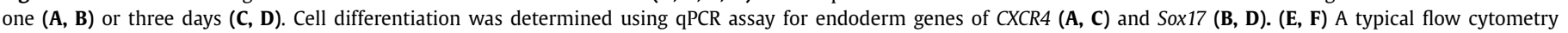

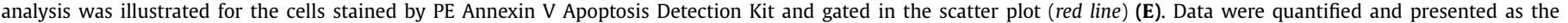
mean \pm SEM of fold of expression in three replicates in each case (F).

trol), which were grouped into the second phase of hepatic differentiation. The impact of CS extracts on hepatic differentiation was illustrated by two typical hepatic biomarkers, ALB and CK18, where actin and nucleus staining served as references. In all four cases, the cells became fully spread and tightly connected, presenting an epithelial cell-like shape. CK18s were mainly expressed in the cytoplasm (Fig. 6A1-A4), while ALBs tended to distribute over entire cells in a sheet-like manner (Fig. 6A5-A8). Similar immunostaining observations were found in the $S^{\text {low }} \mathrm{D}^{\text {null }} \mathrm{P}^{\text {null }} \mathrm{M}^{\text {null }}$ case (Fig. 6A9A12). Staining in the three cases was much higher than the control in null CS extracts (Fig. 6A13-A16). Quantitative analysis of normalized MFIs, estimated as the ratio of the intensity of the protein of interest to that of nuclei and then normalized to the controls, indicated that both CK18 and ALB expressions increased significantly in the supplemented CS extracts in the second phase $\left(S^{\text {low }} \mathrm{D}^{\text {null }} \mathrm{P}^{\text {high }} \mathrm{M}^{\text {high }}\right.$ and $\left.\mathrm{S}^{\text {low }} \mathrm{D}^{\text {null }} \mathrm{P}^{\text {low }} \mathrm{M}^{\text {low }}\right)$. Even in null CS extracts in this phase $\left(S^{\text {low }} \mathrm{D}^{\text {null }} \mathrm{P}^{\text {null }} \mathrm{M}^{\text {null }}\right)$, the MFIs for the two biomarkers were still higher than those in the control, supporting the validity of optimizing the DE lineage cells for hepatic differentiation in the first phase (Fig. 6B, C). By contrast, CK18 and ALB gene expressions were likely enhanced in the supplemented CS extracts in the second phase (first two bars), while no differences were observed in gene expressions between first phase-optimized DE lineage cells and original H9 cells (latter two bars) (Fig. 6D, E). Simple western analysis further confirmed the above observations at the protein level with enhanced expressions of CK18 and ALB in CSactivated HLCs (Fig. 6F-H), that is, adding CS extracts in the second phase could enhance HLC differentiation of the optimized DE lineage cells.

\section{5. hESC-derived HLCs display liver-specific functions}

Maturity and functionality of obtained HLCs was tested. Daily optical observations indicated that the cells grew into large aggregates during the addition of high concentrations of CS extracts into HLC-specific inducing medium at the first day of Pre-H stage. At the end of an additional two days of HLC induction, the apparent protuberant ridges were observed inside the flattened cell monolayer (Fig 7A; yellow arrows), presenting similar features of hepatic plate-like configuration [38].

To further identify the maturity of CS-activated HLCs from the optimized DE lineage cells, typical tests of liver-specific functions were conducted. First, immunostaining of glycogen synthesis indicated that the HLCs are functional in this regard (Fig. 7B). Specifically, higher staining was observed at the low CS concentration $\left(S^{\text {low }} \mathrm{D}^{\text {null }} \mathrm{P}^{\text {low }} \mathrm{M}^{\text {low }}\right)$ or in null CS extracts $\left(\mathrm{S}^{\text {low }} \mathrm{D}^{\text {null }} \mathrm{P}^{\text {null }} \mathrm{M}^{\text {null }}\right)$, while similar lower staining was observed at the high CS concentration ( $\mathrm{S}^{\text {low }} \mathrm{D}^{\text {null }} \mathrm{P}^{\text {high }} \mathrm{M}^{\text {high }}$ ) or in control cases. These results implied that, at least, adding CS extracts at low concentrations in the second phase favors glycogen synthesis in HLCs. Second, the capacity of selective phagocytosis was tested by engulfing indocyanine green (ICG) (Fig. 7C). Immunostaining of ICG engulfment was quite low, indicating incomplete maturity of HLCs, as expected [39, 40]. Meanwhile, ICG engulfment at low CS concentrations ( $S^{\text {low }} \mathrm{D}^{\text {null }} \mathrm{P}^{\text {low }} \mathrm{M}^{\text {low }}$ ) seemed slightly higher even though no significant difference was observed among the four cases, being likely consistent with the above observations regarding glycogen synthesis. Third, ALB secretion was monitored for these CSactivated HLCs (Fig. 7D). Again, the secretion was relatively low 

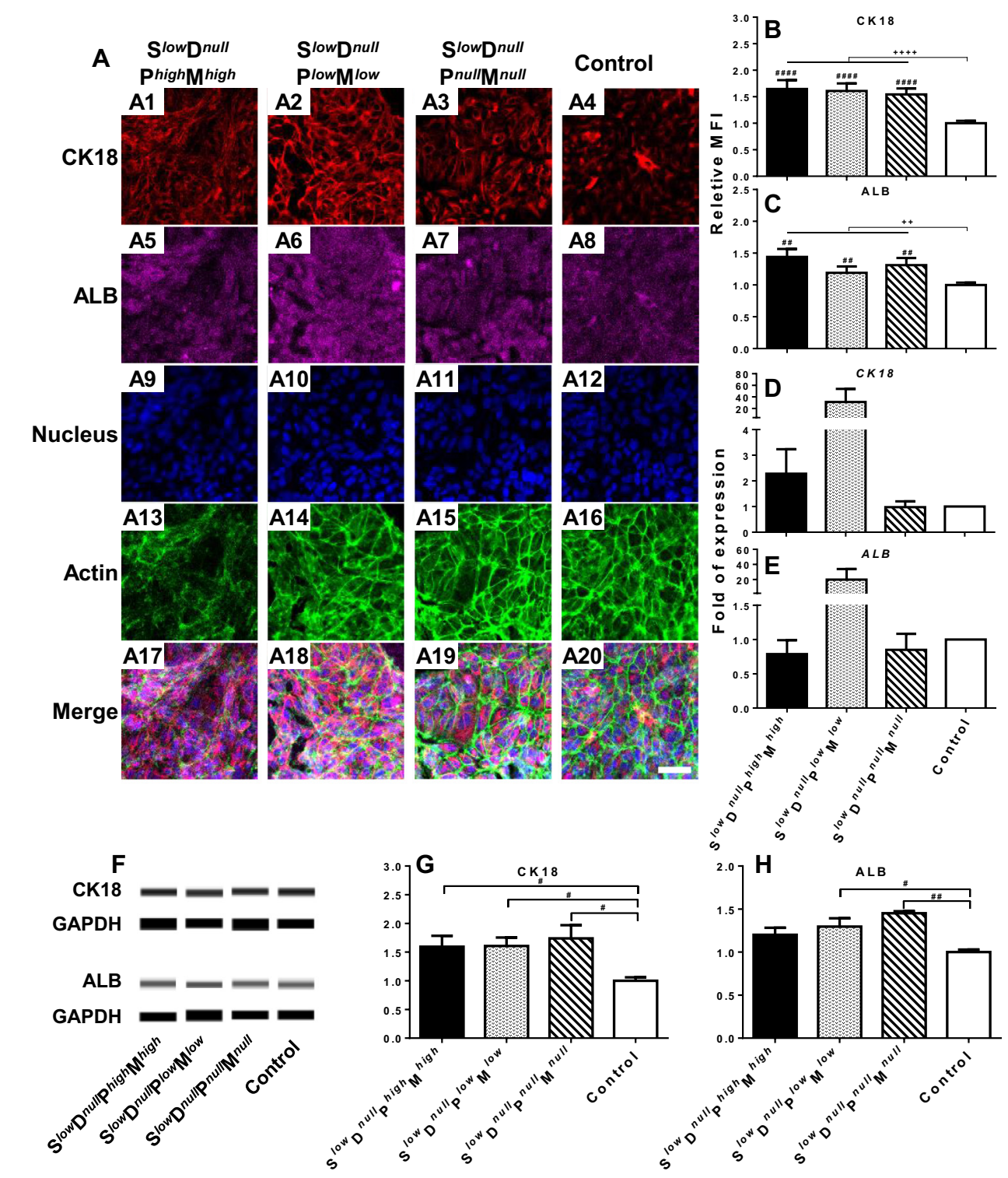

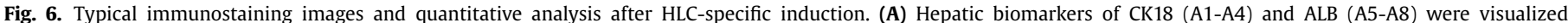

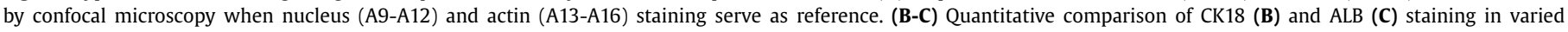

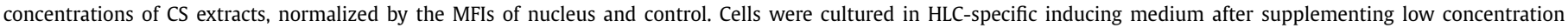

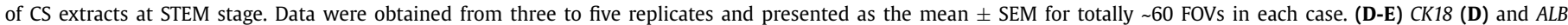

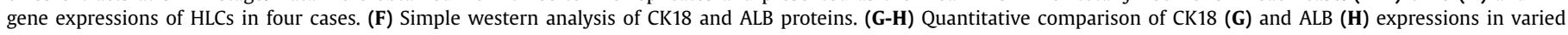

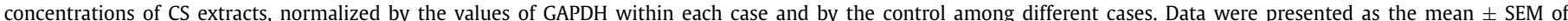

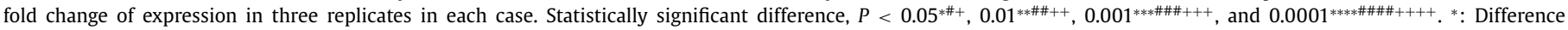
between any two specific cases. \#: Difference between any one specific case and the control. ${ }^{+}$: Difference between any two groups of the lumped cases.

( $<10 \mathrm{ng} / \mathrm{ml}$ per million cells per day), anticipating that further maturation is required. Nevertheless, ALB secretion was seemingly higher for optimized DE lineage cells than controls when supplementing CS extracts at Pre-H and $\mathrm{M}-\mathrm{H}$ stages $\left(\mathrm{S}^{\text {low }} \mathrm{D}^{\text {null }} \mathrm{P}\right.$ high $\mathrm{M}^{\text {high }}$ and $\left.S^{\text {low }} \mathrm{D}^{\text {null }} \mathrm{P}^{\text {low }} \mathrm{M}^{\text {low }}\right)$ or not $\left(\mathrm{S}^{\text {low }} \mathrm{D}^{\text {null }} \mathrm{P}^{\text {null }} \mathrm{M}^{\text {null }}\right)$. Excluding the two cases with large variations, adding CS extracts at a low concentration ( $S^{l o w} D^{\text {null }}{ }^{\text {low }} \mathrm{M}^{\text {low }}$ ) could markedly enhance ALB secretion, further supporting the effectiveness of CS extracts in promoting hepatic maturation.

Adding CS extracts spanning over Pre-H and $\mathrm{M}-\mathrm{H}$ stages also promoted the expression of CK18 and ALB (Figure S5A). Analysis of normalized MFIs indicated that CK18 expression increased in the supplemented CS extracts at two concentrations used (Figure S5B), whereas ALB expression was higher at the high concentration (Figure S5C). Meanwhile, gene expressions of CK18 and ALB seemed indifferent in these cases (Figure S5D, E). Tests of glycogen synthesis immunostaining (Figure S6A), ICG engulfment (Figure S6B), and ALB secretion (Figure S6C) indicate a strengthened hepatic phenotype, at least in the $S^{\text {low }} \mathrm{D}^{\text {null }} \mathrm{P}^{\text {low }} \mathrm{M}^{\text {low }}$ case, highlighting the potentiation of CS extracts.

\subsection{Functional validation of CS-activated $\mathrm{HLCs}$ in $\mathrm{CCl}_{4}$-treated mice}

To further test the functionality of CS-activated HLCs in repairing liver injury, both H9-derived HLCs from CS activation and conventional differentiation without CS were transplanted into $\mathrm{CCl}_{4}$-treated mice (Fig. 8A) when feeding wild type (WT) for the same duration as controls. In contrast to the $\mathrm{CCl}_{4}$-treated group, in which liver injury indicated by histological and histochemical staining revealed serrated edges, ballooning degeneration (arrows), apoptotic cells (arrowheads), and markedly increased col- 

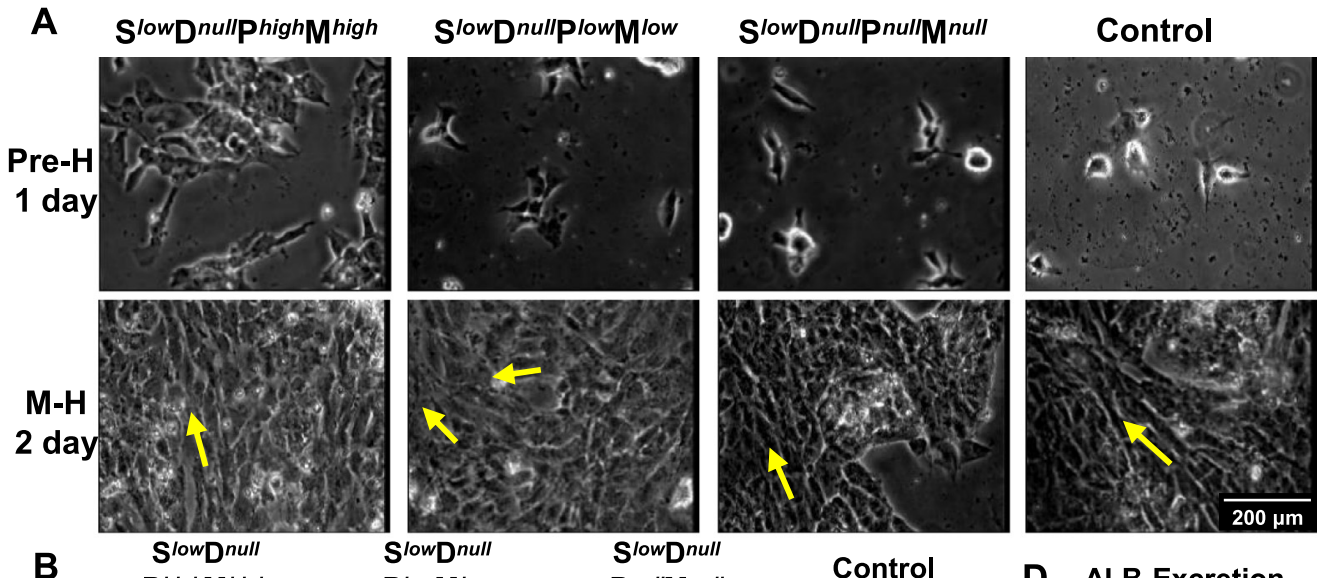

B

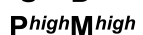
Plow Mlow PnullMnull

Control
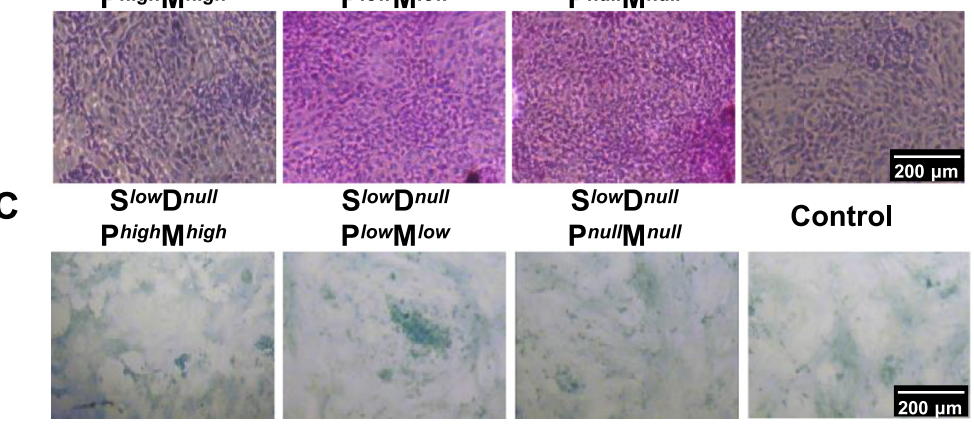

D ALB Excretion

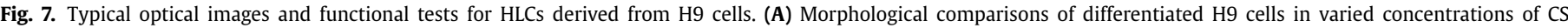

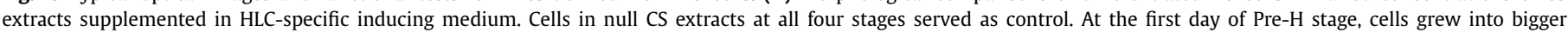

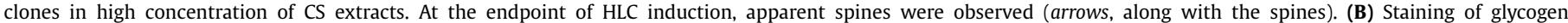

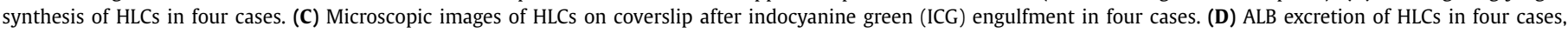

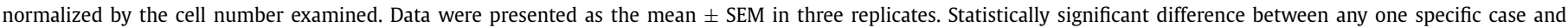

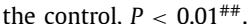

lagen fibers (swallowtail) (Fig. 8B), and serum tests showed enhanced AST and ALT activities (Fig. 8C, D), and the control HLC group with minor inhibition of liver fibrosis, the $S^{\text {low }} \mathrm{D}^{\text {null }} \mathrm{P}^{\text {low }} \mathrm{M}^{\text {low }}$ strategy (CS-activated HLC group) demonstrated effective liver injury repair. Confocal imaging indicated that CS-activated HLCs were able to reside continuously, but control HLCs presented in a dispersed manner in the liver three days (Fig. 8E) and four weeks (Fig. 8F) after injection, compared to the null HLCs in WT or $\mathrm{CCl}_{4}$-treated mice. Long-term feeding post-injection indicated that transplanted HLCs were able to survive up to four weeks in the liver (Fig. 8E, F). 3D slicing and reconstruction of confocal images demonstrated typical residence, with sparse residence for control HLCs (Supplemental Movie S1) and accumulated residence for activated HLCs (Supplemental Movie S2). IVIS tests confirmed HLC residence in the injured liver with highest radiant efficiency and largest area of activated HLCs (Fig. 8G), indicating the highest efficiency of HLC residence. This observation was consistent with the turnover of the fibrotic phenotype among the four cases, as seen in the dramatic reduction of surface roughness in the CSactivated HLC group (Fig. 8H). All observed liver optical images are summarized in Figure S7 for reference, especially illustrating the smoother surface of liver tissue with CS activation (last row in Figure S7B). This turnover was confirmed by histological or histochemical staining and serum tests at Week 4 post-transplantation (Fig. 8I, J). Here, the fibrotic phenotype of the injured liver in $\mathrm{CCl}_{4}$ treated mice was partly reversed by injecting control HLCs, while CS-activated HLC transplantation induced significant recovery compared to $\mathrm{CCl}_{4}$-treated mice without HLCs (Fig. 8I). Furthermore, $\mathrm{CCl}_{4}$-treated mice exhibited high AST activity and control HLCinjected mice revealed minimal AST reduction, while CS-activated
HLC-transplantation significantly reduced AST activity to normal levels as compared with WT mice (Fig. 8J). By contrast, ALT activity was relatively high with HLC transplantation compared to WT mice (Fig. 8K). Collectively, these tests using $\mathrm{CCl}_{4}$-treated mice indicate that the injured livers were repaired by transplantation of CS-activated HLCs, which demonstrates the potential application of regulating hepatic differentiation from $\mathrm{H} 9$ cells using CS-extracts.

Taken together, adding CS extracts over Pre-H and M-H stages was effective in ridge formation, biomarker expression, and functional implementation in directing hepatic differentiation of $\mathrm{H9}$ cells. Low concentrations of CS extracts favor the typical functions of differentiated HLCs and the turnover of a fibrosis-like phenotype, which could be integrated with the protocol in optimizing $\mathrm{DE}$ lineage cells and serve as a practical procedure for future applications in liver injury repair.

\section{Discussion}

Liver disease is one of the primary causes of death globally. Stem cell-based therapy could serve as a promising therapeutic method for patients with end-stage liver diseases, which may alleviate the need for liver transplantation. Previous research has primarily focused on utilizing the differentiation potential of stem cells and inducing hESCs into hepatocyte-like cells via biochemical factors in hepatic differentiation. In this study, we demonstrated, for the first time, that CS extracts derived from CS bioceramics enhance hepatic differentiation of hESCs, combined with a modified four-stage differentiation strategy. High concentrations of CS extracts were found to enhance the initial DE differentiation, followed by the persistent role of low CS concentrations in longterm DE differentiation. The optimized cells from the DE lineage 


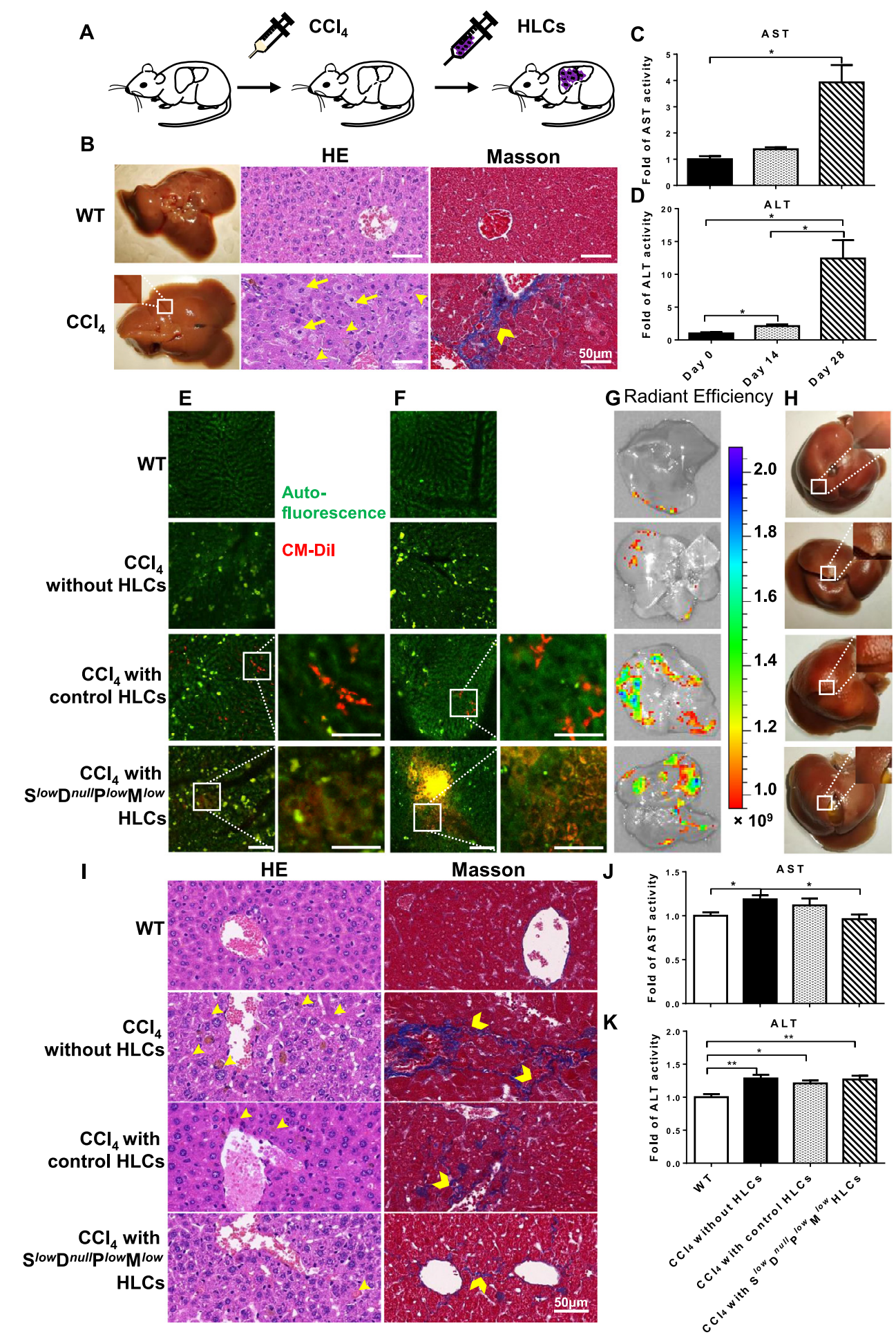

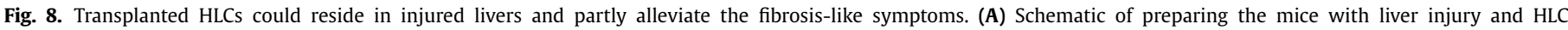

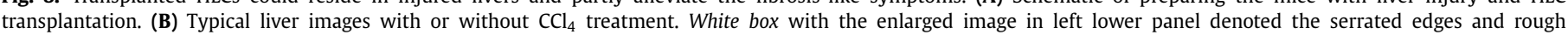

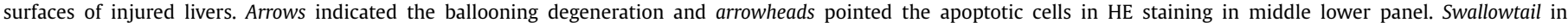

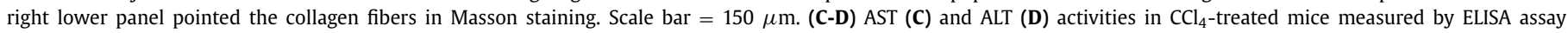

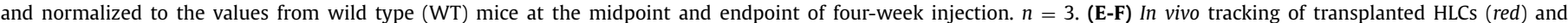

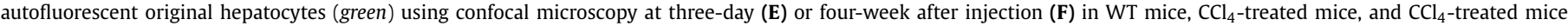

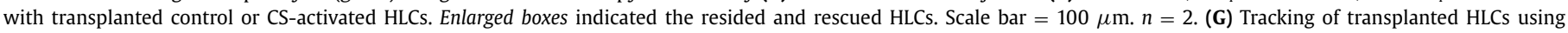

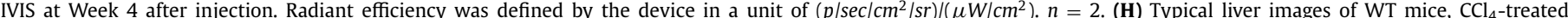

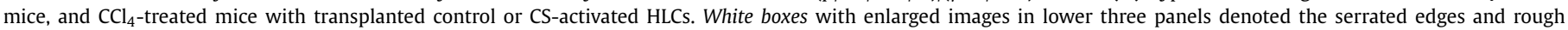

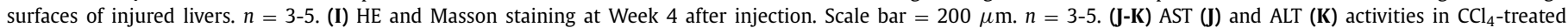
and HLC-transplanted mice measured by ELISA assay and normalized to the values to WT mice at Week 4 after injection. ${ }^{*} P<0.05$ and ${ }^{* *} P<0.05$. 
further promote hepatic differentiation into functional HLCs in CS extract concentration- and order of addition-dependent manners. This work underlined the importance of CS extracts in hESC differentiation into HLCs.

During hESC differentiation, the cells originally compacted as the clones or spheroids loosen into single cells, manifesting as the initiation of differentiation [41-43]. In this study, one-day DE induction clarifies the clone into a main body and a surrounding region, and presents a positive correlation between main body size or single cell and CS concentration (Fig.. 2 and S3), which agrees with observations on literature [44,45]. Moreover, pancreatic cells and hepatocytes originated from DE specifically express specified markers SOX17, CXCR4, GSC, KRT8, and BMP2 and serves as a key stage in hepatic differentiation [46]. Generally, the DE stage lasts three to seven days $[20,47,48]$ to ensure complete differentiation, although DE markers could only express for $24 \mathrm{~h}$ after adding the induction factors of activin A and Wnt-3a [30,49]. Several studies focus on the types of inducing factors and the concentration of these factors [50-52], but only a few address the order of addition of multiple factors presented in the induction medium [53], and even less regard bioactive inorganic ions. Our data not only support the observations with visible expressions of two typical markers, SOX17 and CXCR4, at the DE stage, but also propose the concentration- and order of addition-dependences of CS extracts. In initial DE induction, SOX17 expression in $S^{\text {high }} \mathrm{D}^{\text {high }}$ and $S^{\text {high }} \mathrm{D}^{\text {null }}$ cases at the high CS concentration is higher, whereas CXCR4 expression in $S^{\text {low }} \mathrm{D}^{\text {low }}$ case at the low CS concentration is lower than those of controls (Fig. 3), indicating that adding high CS concentrations at the STEM stage enhances initial DE differentiation of H9 cells. In late DE induction, CXCR4 and SOX17 expressions at low CS concentrations are significantly higher than controls, especially in $S^{\text {low }} \mathrm{D}^{\text {null }}$ or $\mathrm{S}^{\text {null }} \mathrm{D}^{\text {low }}$ case (Fig. 4). Gene expression related to the DE lineage further consolidates the optimized combination of CS concentration and order of addition for DE differentiation of H9 cells (Fig. 5A-D). These cues further the understanding of the types, concentration, and order of addition of both biochemical factors and bioactive inorganic ions in inducing DE differentiation.

Further to the above-mentioned results and our early work in the effects of CS extracts on stemness maintenance in short-term induction and mesodermal differentiation in long-term induction [29], CS extracts might present differential effects on cellular phenotypes at distinct stages, such as maintaining stemness and facilitating differentiation [54,55]. Specifically, the low CS concentration promotes stemness maintenance of $\mathrm{H9}$ cells over short periods [29], consistent with the current observations that low CS concentration is not favorable for DE differentiation (Fig. 3), and implying a dominant role of CS extracts in stemness maintenance, especially at the STEM stage. In contrast, the high CS concentration promotes DE differentiation immediately with high expressions of CXCR4 and SOX17, followed by persistent DE differentiation at low CS concentrations, suggesting a dominant role of CS extracts in directed differentiation over extended periods beyond the STEM stage. A similar observation indicates that low concentrations of $\mathrm{Si}$ and $\mathrm{Sr}$ ions synergistically stimulate cell proliferation without losing stemness, while high concentrations are able to direct osteogenic differentiation of hBMSCs [56]. This biphasic effect of ion concentration is evident, of which the mechanism remains to be further studied. For example, Wnt $/ \beta$-catenin signaling is crucial in DE differentiation [57,58] and in osteogenic differentiation from human urine-derived stem cells (hUSCs) [22], implying a potential candidate for molecular mechanisms in hepatic differentiation of hESCs. Moreover, the potential signaling pathways and the uniqueness or universality of calcium silicate and other inorganic bioactive ions are also critical issues in directing ESC differentiation at the different stages.
Except for the impacts on initial DE differentiation, bioactive inorganic ions could also regulate the lineage-specific terminal differentiation. For example, CS and its analogs promote the differentiation of MSCs into osteoblastic cells [23,27,59]. $\mathrm{Ca}_{3} \mathrm{Si} / \mathrm{CaCl}_{2}$ composites with polyethylene glycol (PEG) enhances the proliferation and alkaline phosphate activity of hDPSCs [60]. In fact, $\mathrm{Si}$ ions and the related compounds are essential nutrients responsible for many biological processes. In the human body, Si ions amount to $0.01 \%$ of body weight (1-2 $\mathrm{g}$ in total), which are lower than Fe and $\mathrm{Zn}$ ions $[61,62]$. The concentration of $\mathrm{Si}$ ions in serum ranges between 24 and $31 \mu \mathrm{g} / \mathrm{dL}$. After uptake, Si ions participate in multiple functions, such as metabolism and excretion, and especially in liver-specific functions [63]. In vitro tests exemplify that Si ions are favorable for BMSCs for persistent adipogenesis once cell differentiation is initiated by adipogenic-inducing medium [56,64]. The reasons we used CS extracts instead of calcium silicate particles lie in two aspects: Firstly, previous studies have demonstrated that the ions released from CS are the main bioactive factors to stimulate cellular activity. Secondly, one of the liver tissue engineering problems, that is, the activation of stem cells in vitro as seed cells for transplantation, can be solved by simply applying the bioactive ions of CS extracts in vitro for the cell culture experiments. Our results implied that functional differences of hESCs presented in CS extracts are mainly attributed to the changes of Si ions (Table 1). Meanwhile, apparent ridges among neighbouring cells are observed inside the HLC monolayer at the M-H stage (Fig. 7), serving as the potential progenitor structure of hepatic plates $[38,65]$. Cells in HLC-specific induction are able to express hepatic markers of CK18 and ALB (Fig. 6), corroborating the efficiency of the differentiation strategies used [32,66-70]. Adding high, low, or null concentrations of CS extracts at Pre-H and M$\mathrm{H}$ stages do not impact marker expression as long as H9 cells are optimized by low CS concentrations at the STEM stage. We examined another set of order-of-CS-addition only at Pre-H and $\mathrm{M}-\mathrm{H}$ stages. Here CK18 expression is significantly higher in both $\mathrm{S}^{\text {null }} \mathrm{D}^{\text {null }} \mathrm{P}^{\text {high }} \mathrm{M}^{\text {high }}$ and $\mathrm{S}^{\text {null }} \mathrm{D}^{\text {null }} \mathrm{P}^{\text {low }} \mathrm{M}^{\text {low }}$ cases, while the cells express higher ALB at protein level only in the $S^{\text {null }} \mathrm{D}^{\text {null }}$ phigh $\mathrm{M}^{\text {high }}$ case, as compared to controls (Figure S5). These results indicate that CS extracts only added at Pre- $\mathrm{H}$ and $\mathrm{M}-\mathrm{H}$ stages could enhance hepatic differentiation, but less effectively and with nonincreasing $C K 18$ and $A L B$ gene expressions, compared with those adding CS extracts at the STEM stage. Additionally, H9 cells readily react to high, but not low CS concentrations, indicating the concentration sensitivity is similar to literature reporting that osteoblasts differentiated from USCs present the enhanced Runx2 gene expression at high CS concentrations, while no significant difference is found between low concentrations and controls [22]. Further optimizing the current protocol is required to isolate the possible contamination of CS-based cholangiocyte differentiation in the HLCs population derived from hESCs and to enhance their maturity and functionality.

Stem cell differentiation and maturation are critical for the success of tissue repair and cell therapy in vivo. Generating HLCs from pluripotent stem cells remains a major challenge in that the differentiated hepatocytes usually present immature functions compared to primary hepatocytes isolated from liver [71]. Great efforts are made to obtain mature hepatocytes in addition to various factors mentioned above. For example, HLCs induced from hESCs (Royan H5) on three-dimensional nanofibrillar surfaces exhibit high glycogen storage and ICG uptake activity, compared to those cultured in the non-nano-group [65], presumably due to the fact that hepatic canalicular structures are greatly lost in two-dimensional culture [72]. H9 cells seeded on Cytodex 1 or 3 microcarriers can be induced into HLCs with high albumin secretion, but CYP3A4 activity and urea production are not improved [73]. Small molecules are also used to develop handy and cost-effective inducing strate- 
gies, attempting to produce HLCs at comparable maturity as those from growth factor-based strategies [16,74]. Along this line of reasoning, applying CS extracts could serve as a simple and efficient method to improve HLC maturation. Our results present high glycogen staining or ALB excretion and similar ICG uptake for H9 cells optimized at the STEM stage, even though no CS concentration dependence is observed at the Pre-H stage (Fig. 7B-D and S6). Low ALB secretion is presumably attributed to the short-term maturation of HLCs at the M-H stage [40,75], which could be improved by extending the duration of the $\mathrm{M}-\mathrm{H}$ stage to enhance the maturity of HLCs. Evidently, comparisons of CS-directed approach with those nanofiber- or Cytodex microcarrier-induced ones could be helpful to augment HLCs efficacy. Another critical issue is the proof of therapeutic functions of CS-activated HLCs in vivo. In the present study, we demonstrated that the implanted CS-activated HLCs significantly reduced liver injury in $\mathrm{CCl}_{4}$-treated mice and these HLCs, exposed to the $S^{\text {low }} \mathrm{D}^{\text {null }} \mathrm{P}^{\text {low }} \mathrm{M}^{\text {low }}$ treatment protocol, alleviate the fibrosis-like symptoms (Fig. 8), thereby confirming the availability of CS-activated HLCs from H9 cells for repairing liver injuries. This is mainly because CS-activated HLCs present hepatocyte-like phenotype and functionality, as seen in the enhanced ALB and CK 18 expressions (Fig. 6) and the increased glycogen synthesis or ICG engulfment (Fig. 7). In fact, evidence indicates that HLCs are favored to repair liver injury [76-80]. We also found that HLCs are able to survive up to four weeks with better hepatocyte-like morphology (Fig. 8E-G), smoother edges of liver tissue, thinner collagen fibrils, and much lower AST activity (Fig. 8H-K), which promote the turnover of $\mathrm{CCl}_{4}$-induced liver injury (Fig. 8). Moreover, it is likely that CS-activated HLCs presented the more crucial effects than control HLCs, since the former presented higher survival rate (Fig. 8E-F), thinner collagen fibrils (Fig. 8I) and less AST activity (Fig. 8J) at four-week post-transplantation. These results imply that CS-activated HLCs exhibit defined hepatic functions and could play a potential role in repairing liver injury.

\section{Conclusions}

Inorganic bioactive ions released from calcium silicate bioceramics enhance hepatic differentiation of hESCs in vitro. This enhancement is CS concentration- and order of addition-dependent. High CS concentration promotes DE differentiation immediately while low CS concentration directs DE differentiation at a later stage. Adding low concentrations of CS extracts at the STEM stage could enhance the capacity of hepatic differentiation, the maturation of hepatocyte-like cells, and the turnover of fibrosislike phenotype in mice. These results imply that soluble chemical factors such as bioactive ions released from biomaterials are highly effective in obtaining functional hepatocytes from hESCs, and biomaterial-based strategies might present an effective approach for obtaining functional hepatocytes for liver injury repair and liver cell therapy. Future studies are required on improving the maturity of CS-activated HLCs and testing their functionality in liver injury repair with various injury models.

\section{Data availability statement}

The data sets used and/or analyzed during the current study are available from the corresponding author on reasonable request.

\section{Credit Authorship Contribution Statement}

Lu Zheng: Investigation, Methodology, Formal analysis, Data curation, Writing - original draft. Dongyuan Lü: Investigation, Formal analysis, Data curation, Writing - original draft, Funding acquisition. Fan Zhang: Methodology, Investigation. Min Xing: Investigation. Xiaoya Wang: Investigation. Xiaohua Jia: Methodol- ogy, Investigation. Xinyu Shu: Investigation. Peiwen Li: Investigation. Shouqin Lü: Conceptualization, Formal analysis, Data curation, Funding acquisition. Jiang Chang: Conceptualization, Writing - review \& editing, Supervision, Validation. Mian Long: Conceptualization, Writing - review \& editing, Supervision, Validation, Project administration, Funding acquisition.

\section{Supporting materials}

Supporting materials associated with this article can be found, in the online version, at dio: $\mathrm{xxx}$.

\section{Declaration of Competing Interest}

The authors declare that they have no known competing financial interests or personal relationships that could have appeared to influence the work reported in this paper.

\section{Acknowledgements}

The authors thank the technical assistances from Dr. Jie Tian and his team from Institute of Automation, Chinese Academy of Sciences. This work was supported by National Natural Science Foundation of China grants 91642203, 31627804, 31870931, and Frontier Science Key Project of Chinese Science Academy grant QYZDJ-SSW-JSC018.

\section{Supplementary materials}

Supplementary material associated with this article can be found, in the online version, at doi:10.1016/j.apmt.2020.100730.

\section{References}

[1] G.K. Michalopoulos, M.C. DeFrances, Liver Regeneration, Science 276 (1997) 60-66.

[2] A.T. Wan Song, V.I. Avelino-Silva, R.A. Arruda Pecora, V. Pugliese, L.A. Carneiro D'Albuquerque, E. Abdala, Liver transplantation: fifty years of experience, World J. Gastroenterol. 20 (2014) 5363-5374.

[3] K.A. Soltys, K. Setoyama, E.N. Tafaleng, A.S. Gutierrez, J. Fong, K. Fukumitsu, T. Nishikawa, M. Nagaya, R. Sada, K. Haberman, R. Gramignoli, K. Dorko, V. Tahan, A. Dreyzin, K. Baskin, J.J. Crowley, M.A. Quader, M. Deutsch, C. Ashokkumar, B.L. Shneider, R.H. Squires, S. Ranganathan, M. Reyes-Mugica, S.F. Dobrowolski, G. Mazariegos, R. Elango, D.B. Stolz, S.C. Strom, G. Vockley, J. Roy-Chowdhury, M. Cascalho, C. Guha, R. Sindhi, J.L. Platt, I.J. Fox, Host conditioning and rejection monitoring in hepatocyte transplantation in humans, J. Hepatol. 66 (2017) 987-1000.

[4] R.H. Costa, V.V. Kalinichenko, A.X.L. Holterman, X.H. Wang, Transcription factors in liver development, differentiation, and regeneration, Hepatology 38 (2003) 1331-1347.

[5] T. Miki, A. Ring, J. Gerlach, Hepatic differentiation of human embryonic stem cells is promoted by three-dimensional dynamic perfusion culture conditions, Tissue Eng. Part C-Methods 17 (2011) 557-568.

[6] S.J. Forbes, S. Gupta, A. Dhawan, Cell therapy for liver disease: from liver transplantation to cell factory, J. Hepatol. 62 (2015) S157-S169.

[7] V. Volarevic, J. Nurkovic, N. Arsenijevic, M. Stojkovic, Concise Review, Therapeutic potential of mesenchymal stem cells for the treatment of acute liver failure and cirrhosis, Stem Cells 32 (2014) 2818-2823.

[8] A. Trounson, C. McDonald, Stem cell therapies in clinical trials: progress and challenges, Cell Stem Cell 17 (2015) 11-22.

[9] S.W. Lane, D.A. Williams, F.M. Watt, Modulating the stem cell niche for tissue regeneration, Nat. Biotechnol. 32 (2014) 795-803.

[10] J.A. Thomson, J. Itskovitz-Eldor, S.S. Shapiro, M.A. Waknitz, J.J. Swiergiel, V.S. Marshall, J.M. Jones, Embryonic stem cell lines derived from human blastocysts, Science 282 (1998) 1145-1147

[11] C.B. Ware, A.M. Nelson, B. Mecham, J. Hesson, W. Zhou, E.C. Jonlin, A.J. Jimenez-Caliani, X. Deng, C. Cavanaugh, S. Cook, P.J. Tesar, J. Okada, L. Margaretha, H. Sperber, M. Choi, C.A. Blau, P.M. Treuting, R.D. Hawkins, V. Cirulli, H. Ruohola-Baker, Derivation of Naive human embryonic stem cells, PNAS 111 (2014) 4484-4489.

[12] D.Y. Lü, C.H. Luo, C. Zhang, Z. Li, M. Long, Differential regulation of morphology and stemness of mouse embryonic stem cells by substrate stiffness and topography, Biomaterials 35 (2014) 3945-3955.

[13] J. Cai, Y. Zhao, Y. Liu, F. Ye, Z. Song, H. Qin, S. Meng, Y. Chen, R. Zhou, X. Song Y. Guo, M. Ding, H. Deng, Directed differentiation of human embryonic stem cells into functional hepatic cells, Hepatology 45 (2007) 1229-1239.

[14] T. Touboul, N.R.F. Hannan, S. Corbineau, A. Martinez, C. Martinet, S. Branchereau, S. Mainot, H. Strick-Marchand, R. Pedersen, J. Di Santo, 
A. Weber, L. Vallier, Generation of functional hepatocytes from human embryonic stem cells under chemically defined conditions that recapitulate liver development, Hepatology 51 (2010) 1754-1765.

[15] R. Siller, S. Greenhough, E. Naumovska, G.J. Sullivan, Small-molecule-driven hepatocyte differentiation of human pluripotent stem cells, Stem Cell Reports 4 (2015) 939-952.

[16] F. Tasnim, D. Phan, Y.C. Toh, H. Yu, Cost-effective differentiation of hepatocytelike cells from human pluripotent stem cells using small molecules, Biomaterials 70 (2015) 115-125.

[17] D.S. Varghese, T. Alawathugoda, S.A. Ansari, Fine tuning of hepatocyte differentiation from human embryonic stem cells: growth factor vs. small molecule-based approaches, Stem Cells Int. 2019 (2019) (2019) 5968236.

[18] T. Ishikawa, M. Kobayashi, S. Yanagi, C. Kato, R. Takashima, E. Kobayashi, K. Hagiwara, T. Ochiya, Human induced hepatic lineage-oriented stem cells: autonomous specification of human ips cells toward hepatocyte-like cells without any exogenous differentiation factors, PLoS One 10 (2015) e0123193.

[19] A.A. Palakkan, R. Drummond, R.A. Anderson, S. Greenhough, K. Tv, D.C. Hay, J.A. Ross, Polarisation and functional characterisation of hepatocytes derived from human embryonic and mesenchymal stem cells, Biomed. Reports 3 (2015) 626-636.

[20] T. Touboul, S. Chen, C.C. To, S. Mora-Castilla, K. Sabatini, R.H. Tukey, L.C. Laurent, Stage-specific regulation of the WNT/beta-catenin pathway enhances differentiation of hESCs into hepatocytes, J. Hepatol. 64 (2016) 1315-1326.

[21] K. Takayama, M. Inamura, K. Kawabata, K. Katayama, M. Higuchi, K. Tashiro, A. Nonaka, F. Sakurai, T. Hayakawa, M.K. Furue, H. Mizuguchi, Efficient generation of functional hepatocytes from human embryonic stem cells and induced pluripotent stem cells by hnf4 alpha transduction, Mol. Ther. 20 (2012) 127-137.

[22] J. Guan, J. Zhang, S. Guo, H. Zhu, Z. Zhu, H. Li, Y. Wang, C. Zhang, J. Chang, Human urine-derived stem cells can be induced into osteogenic lineage by silicate bioceramics via activation of the Wnt/beta-catenin signaling pathway, Biomaterials 55 (2015) 1-11.

[23] Y. Han, Q. Zeng, H. Li, J. Chang, The calcium silicate/alginate composite: preparation and evaluation of its behavior as bioactive injectable hydrogels, Acta Biomater. 9 (2013) 9107-9117.

[24] W. Peng, W. Liu, W. Zhai, L. Jiang, L. Li, J. Chang, Y. Zhu, Effect of tricalcium silicate on the proliferation and odontogenic differentiation of human dental pulp cells, J. Endod. 37 (2011) 1240-1246.

[25] N.-J. Chang, Y.-W. Chen, D.-E. Shieh, H.-Y. Fang, M.-Y. Shie, The effects of injectable calcium silicate-based composites with the chinese herb on an osteogenic accelerator in vitro, Biomed. Mater. 10 (2015) 055004.

[26] T.T. Hsu, C.T. Kao, Y.W. Chen, T.H. Huang, J.J. Yang, M.Y. Shie, The synergistic effects of $\mathrm{CO}_{2}$ laser treatment with calcium silicate cement of antibacterial, osteogenesis and cementogenesis efficacy, Laser Phys. Lett. 12 (2015) (2015) 055602.

[27] A.A. Eid, K.A. Hussein, L.N. Niu, G.H. Li, I. Watanabe, M. Al-Shabrawey, D.H. Pashley, F.R. Tay, Effects of tricalcium silicate cements on osteogenic differentiation of human bone marrow-derived mesenchymal stem cells in vitro, Acta Biomater. 10 (2014) 3327-3334.

[28] Y.-W. Chen, T.-T. Hsu, K. Wang, M.-Y. Shie, Preparation of the fast setting and degrading Ca-Si-Mg cement with both odontogenesis and angiogenesis differentiation of human periodontal ligament cells, Mater. Sci. Eng. C-Mater. Biol. Appl. 60 (2016) 374-383.

[29] F. Zhang, D.Y. Lü, H.Y. Li, C.H. Luo, J. Chang, M. Long, Bioactive calcium silicate extracts regulate the morphology and stemness of human embryonic stem cells at the initial stage, RSC Adv. 6 (2016) 104666-104674.

[30] J. Huang, X. Guo, W. Li, H. Zhang, Activation of Wnt/beta-catenin signalling via GSK3 inhibitors direct differentiation of human adipose stem cells into functional hepatocytes, Sci. Rep. 7 (2017) 40716.

[31] Y. Nagamoto, K. Tashiro, K. Takayama, K. Ohashi, K. Kawabata, F. Sakurai, M. Tachibana, T. Hayakawa, M.K. Furue, H. Mizuguchi, The Promotion of hepatic maturation of human pluripotent stem cells in 3D co-culture using type I Collagen and Swiss 3T3 cell sheets, Biomaterials 33 (2012) 4526-4534.

[32] N.L. Magner, Y. Jung, J. Wu, J.A. Nolta, M.A. Zern, P. Zhou, Insulin and Igfs enhance hepatocyte differentiation from human embryonic stem cells via the PI3K/AKT pathway, Stem Cells 31 (2013) 2095-2103.

[33] H.Y. Li, J. Chang, Bioactive silicate materials stimulate angiogenesis in fibroblast and endothelial cell co-culture system through paracrine effect, Acta Biomater. 9 (2013) 6981-6991.

[34] J.W Wang, Y. Wu, X. Zhang, F. Zhang, D.Y. Lü, B. Shangguan, Y.X. Gao, M. Long, Flow-enhanced priming of hESCs through H2B acetylation and chromatin decondensation, Stem Cell Res. Therapy 10 (2019) 349.

[35] H. Deng, W.T. Shang, G.H. Lu, P.Y. Guo, T. Ai, C.H. Fang, J. Tian, Targeted and multifunctional technology for identification between hepatocellular carcinoma and liver cirrhosis, ACS Appl. Mater. Interfaces 11 (2019) 14526-14537.

[36] Z. Hu, Y. Qu, K. Wang, X. Zhang, J. Zha, T. Song, C. Bao, H. Liu, Z. Wang, J. Wang, Z. Liu, H. Liu, J. Tian, In vivo nanoparticle-mediated radiopharmaceutical-excited fluorescence molecular Imaging, Nat. Commun. 6 (2015) 7560.

[37] Y. Lv, J. Tian, W. Cong, G. Wang, J. Luo, W. Yang, H. Li, A multilevel adaptive finite element algorithm for bioluminescence tomography, Opt. Express 14 (2006) 8211-8223.

[38] J. Kano, T. Ishiyama, N. Nakamura, T. Iijima, Y. Morishita, M. Noguchi, Establishment of hepatic stem-like cell lines from normal adult porcine liver in A Poly-D-lysine-coated dish with NAIR-1 medium, Vitro Cell. Dev. Biol.-Anim. 39 (2003) 440-448.
[39] A. Ghodsizadeh, H. Hosseinkhani, A. Piryaei, B. Pournasr, M. Najarasl, Y. Hiraoka, H. Baharvand, Galactosylated collagen matrix enhanced in vitro maturation of human embryonic stem cell-derived hepatocyte-like cells, Biotechnol. Lett. 36 (2014) 1095-1106.

[40] A. Mandal, S. Raju, C. Viswanathan, Long-term culture and cryopreservation does not affect the stability and functionality of human embryonic stem cell-derived hepatocyte-like cells, In Vitro Cell. Dev. Biol.-Anim. 52 (2016) $243-251$.

[41] M.M. Daadi, A.-L. Maag, G.K. Steinberg, Adherent self-renewable human embryonic stem cell-derived neural stem cell line: functional engraftment in experimental stroke model, PLoS One 3 (2008) e1644.

[42] S. Avery, G. Zafarana, P.J. Gokhale, P.W. Andrews, The role of SMAD4 in human embryonic stem cell self-renewal and stem cell fate, Stem Cells 28 (2010) 863-873.

[43] J.Y. Tan, G. Sriram, A.J. Rufaihah, K.G. Neoh, T. Cao, Efficient derivation of lateral plate and paraxial mesoderm subtypes from human embryonic stem cells through GSKi-mediated differentiation, Stem Cells Dev. 22 (2013) 1893-1906.

[44] S. Tada, T. Era, C. Furusawa, H. Sakurai, S. Nishikawa, M. Kinoshita, K. Nakao, T. Chiba, S.I. Nishikawa, Characterization of mesendoderm: a diverging point of the definitive endoderm and mesoderm in embryonic stem cell differentiation culture, Development 132 (2005) 4363-4374.

[45] M. Takenaga, M. Fukumoto, Y. Hori, Regulated nodal signaling promotes differentiation of the definitive dndoderm and mesoderm from ES Cells, J. Cell Sci. 120 (2007) 2078-2090.

[46] H. Semb, Expandable Endodermal Progenitors, New tools to explore endoderm and its derivatives, Cell Stem Cell 3 (2008) 355-356.

[47] A.B. McLean, K.A. D’Amour, K.L. Jones, M. Krishnamoorthy, M.J. Kulik, D.M. Reynolds, A.M. Sheppard, H. Liu, Y. Xu, E.E. Baetge, S. Dalton, Activin A efficiently specifies definitive endoderm from human embryonic stem cells only when phosphatidylinositol 3-kinase signaling is suppressed, Stem Cells 25 (2007) 29-38.

[48] A. Hinton, I. Afrikanova, M. Wilson, C.C. King, B. Maurer, G.W. Yeo, A. Hayek A.E. Pasquinelli, A distinct MicroRNA signature for definitive endoderm derived from human embryonic stem cells, Stem Cells Dev. 19 (2010) 797-807.

[49] J.J. Van Oudenhove, R.A. Grandy, P.N. Ghule, R. del Rio, J.B. Lian, J.L. Stein, S.K. Zaidi, G.S. Stein, Lineage-specific early differentiation of human embryonic stem cells requires a G2 cell cycle pause, Stem Cells 34 (2016) 1765-1775.

[50] U. Frandsen, A.D. Porneki, C. Floridon, B.M. Abdallah, M. Kassem, Activin B mediated induction of pdx1 in human embryonic stem cell derived embryoid bodies, Biochem. Biophys. Res. Commun. 362 (2007) 568-574.

[51] A. Korostylev, P.U. Mahaddalkar, O. Keminer, K. Hadian, K. Schorpp, P. Gribbon, H. Lickert, A High-content small molecule screen identifies novel inducers of definitive endoderm, Mol. Metab. 6 (2017) 640-650.

[52] H.K. Bone, A.S. Nelson, C.E. Goldring, D. Tosh, M.J. Welham, A novel chemically directed route for the generation of definitive endoderm from human ebryonic stem cells based on inhibition of GSK-3, J. Cell Sci. 124 (2011) 1992-2000.

[53] M. Johannesson, A. Stahlberg, J. Ameri, F.W. Sand, K. Norrman, H. Semb, FGF4 and retinoic acid direct differentiation of hESCs into PDX1-expressing foregut endoderm in a time- and concentration-dependent manner, PLoS One 4 (2009) e4794.

[54] L. Meseguer-Olmo, S. Aznar-Cervantes, P. Mazon, P.N. De Aza, In Vitro“ behaviour of adult mesenchymal stem cells of human bone marrow origin seeded on a novel bioactive ceramics in the $\mathrm{Ca}_{2} \mathrm{SiO}_{4}-\mathrm{Ca}{ }_{3}\left(\mathrm{PO}_{4}\right)_{2}$ system, J. Mater. Sci.-Mater. Med. 23 (2012) 3003-3014.

[55] B. Bageshlooyafshar, S. Vakilian, M. Kehtari, T. Eslami-Arshaghi, F. Rafeie R. Ramezanifard, R. Rahchamani, A. Mohammadi-Sangcheshmeh, Y. Mostafaloo, E. Seyedjafari, Zinc silicate mineral-coated scaffold improved in vitro osteogenic differentiation of equine adipose-derived mesenchymal stem cells Res. Vet. Sci. 124 (2017) 444-451.

[56] M. Xing, X. Wang, E. Wang, L. Gao, J. Chang, Bone tissue engineering strategy based on the synergistic effects of silicon and strontium ions, Acta Biomater. 72 (2018) 381-395.

[57] P.T.W. Kim, C.J. Ong, Differentiation of definitive endoderm from mouse embryonic stem cells, Results Probl. Cell Differ. 55 (2012) 303-319.

[58] W. Jiang, D. Zhang, N. Bursac, Y. Zhang, WNT3 Is a biomarker capable of predicting the definitive endoderm differentiation potential of hESCs, Stem Cell Reports 1 (2013) 46-52.

[59] X. Zhang, P. Han, A. Jaiprakash, C. Wu, Y. Xiao, A stimulatory effect of $\mathrm{Ca}_{3} \mathrm{ZrSi}_{2} \mathrm{O}_{9}$ bioceramics on cementogenic/osteogenic differentiation of periodontal ligament cells, J. Mater. Chem. B 2 (2014) 1415-1423.

[60] C. Xu, Y. Wen, Y. Zhou, Y. Zhu, Y. Dou, Z. Huan, J. Chang, In vitro self-setting properties, bioactivity, and antibacterial ability of a silicate-based premixed bone cement, Int. J. Appl. Ceram. Technol. 15 (2018) 460-471.

[61] E. Bisse, T. Epting, A. Beil, G. Lindinger, H. Lang, H. Wieland, Reference values for serum silicon in adults, Anal. Biochem. 337 (2005) 130-135.

[62] R. Jugdaohsingh, Silicon and bone health, J. Nutr. Health Aging 11 (2007) 99-110.

[63] W. Goetz, E. Tobiasch, S. Witzleben, M. Schulze, Effects of silicon compounds on biomineralization, osteogenesis, and hard tissue formation, Pharmaceutics 11 (2019) 117.

[64] X. Wang, L. Gao, Y. Han, M. Xing, C. Zhao, J. Peng, J. Chang, Silicon-enhanced adipogenesis and angiogenesis for vascularized adipose tissue engineering, Adv. Sci. 5 (2018) 1800776

[65] Z. Farzaneh, B. Pournasr, M. Ebrahimi, N. Aghdami, H. Baharvand, Enhanced functions of human embryonic stem cell-derived hepatocyte-like cells on 
three-dimensional nanofibrillar surfaces, Stem Cell Rev. Reports 6 (2010) 601-610.

[66] S. Agarwal, K.L. Holton, R. Lanza, Efficient differentiation of functional hepatocytes from human embryonic stem cells, Stem Cells 26 (2008) 1117-1127.

[67] D.C. Hay, J. Fletcher, C. Payne, J.D. Terrace, R.C.J. Gallagher, J. Snoeys, J.R. Black, D. Wojtacha, K. Samuel, Z. Hannoun, A. Pryde, C. Filippi, I.S. Currie, S.J. Forbes, J.A. Ross, P.N. Newsome, J.P. Iredale, Highly efficient differentiation of hESCs to functional hepatic endoderm requires Activin A and Wnt3a signaling, in: Proceedings of the National Academy of Sciences of the United States of America, 105, 2008, pp. 12301-12306.

[68] N. Kim, H. Kim, I. Jung, Y. Kim, D. Kim, Y.-M. Han, Expression profiles of miRNAs in human embryonic stem cells during hepatocyte differentiation, Hepatol. Res. 41 (2011) 170-183.

[69] S. Qu, L. Yan, B. Fang, S. Ye, P. Li, S. Ge, J. Wu, D. Qu, H. Song, Generation of enhanced definitive endoderm from human embryonic stem cells under an albumin/insulin-free and chemically defined condition, Life Sci. 175 (2017) 37-46.

[70] W. Zhou, Z. Hannoun, E. Jaffray, C.N. Medine, J.R. Black, S. Greenhough, L. Zhu, J.A. Ross, S. Forbes, I. Wilmut, J.P. Iredale, R.T. Hay, D.C. Hay, SUMOylation of HNF4 Alpha Regulates Protein Stability and Hepatocyte Function, J. Cell Sci. 125 (2012) 3630-3635.

[71] P. Godoy, W. Schmidt-Heck, K. Natarajan, B. Lucendo-Villarin, D. Szkolnicka, A. Asplund, P. Bjorquist, A. Widera, R. Stober, G. Campos, S. Hammad, A. Sachinidis, U. Chaudhari, G. Damm, T.S. Weiss, A. Nussler, J. Synnergren, K. Edlund, B. Kuppers-Munther, D.C. Hay, J.G. Hengstler, Gene networks and transcription factor motifs defining the differentiation of stem cells into hepatocyte-like cells, J. Hepatol. 63 (2015) 934-942.

[72] Q. Meng, Three-dimensional culture of hepatocytes for prediction of drug-induced hepatotoxicity, Expert Opin. Drug Metab. Toxicol. 6 (2010) 733-746.

[73] Y. Park, Y. Chen, L. Ordovas, C.M. Verfaillie, Hepatic differentiation of human embryonic stem cells on microcarriers, J. Biotechnol. 174 (2014) 39-48.
[74] A. Higuchi, S.S. Kumar, Q.-D. Ling, A.A. Alarfaj, M.A. Munusamy, K. Murugan, S.-T. Hsu, G. Benelli, A. Umezawa, Polymeric design of cell culture materials that guide the differentiation of human pluripotent stem cells, Prog. Polym. Sci. 65 (2017) 83-126.

[75] R. Pal, M.K. Mamidi, A.K. Das, P.K. Gupta, R. Bhonde, A simple and economical route to generate functional hepatocyte-like cells from hESCs and their application in evaluating alcohol induced liver damage, J. Cell. Biochem. 113 (2012) 19-30.

[76] X.L. Wang, S.D. Ge, G. McNamara, C.L. Hao, G.M. Crooks, J.A. Nolta, Albumin-expressing hepatocyte-like cells develop in the livers of immune-deficient mice that received transplants of highly purified human hematopoietic stem cells, Blood 101 (2003) 4201-4208.

[77] D. Campard, P.A. Lysy, M. Najimi, E.F.M. Sokal, Native umbilical cord matrix stem cells express hepatic markers and differentiate into hepatocyte-like cells, Gastroenterology 134 (2008) 833-848.

[78] H. Basma, A. Soto-Gutierrez, G.R. Yannam, L. Liu, R. Ito, T. Yamamoto, E. Ellis, S.D. Carson, S. Sato, Y. Chen, D. Muirhead, N. Navarro-Alvarez, R.J. Wong, J. Roy-Chowdhury, J.L. Platt, D.F. Mercer, J.D. Miller, S.C. Strom, N. Kobayashi, I.J. Fox, Differentiation and transplantation of human embryonic stem cell-derived hepatocytes, Gastroenterology 136 (2009) 990-999.

[79] P. Huang, Z. He, S. Ji, H. Sun, D. Xiang, C. Liu, Y. Hu, X. Wang, L. Hui, Induction of functional hepatocyte-like cells from mouse fibroblasts by defined factors, Nature 475 (2011) 386-U142.

[80] J.A. Heslop, S.A. Duncan, The use of human pluripotent stem cells for modeling liver development and disease, Hepatology 69 (2019) 1306-1316. 